\title{
What are the impacts of reindeer/caribou (Rangifer tarandus L.) on arctic and alpine vegetation? A systematic review
}

\author{
Claes Bernes ${ }^{1 *}$, Kari Anne Bråthen², Bruce C Forbes ${ }^{3}$, James DM Speed ${ }^{4}$ and Jon Moen ${ }^{5}$
}

\begin{abstract}
Background: The reindeer (or caribou, Rangifer tarandus L.) has a natural range extending over much of Eurasia's and North America's arctic, alpine and boreal zones, yet its impact on vegetation is still unclear. This lack of a common understanding hampers both the management of wild and semi-domesticated reindeer populations and the preservation of biodiversity. To achieve a common platform, we have undertaken a systematic review of published studies that compare vegetation at sites with different reindeer densities. Besides biodiversity, we focused on effects on major plant growth forms.
\end{abstract}

Methods: Searches for literature were made using online publication databases, search engines, specialist websites and bibliographies of literature reviews. Search terms were developed in English, Finnish, Norwegian, Russian and Swedish. Identified articles were screened for relevance based on titles, abstracts and full text using inclusion criteria set out in an a priori protocol. Relevant articles were then subject to critical appraisal of susceptibility to bias. Data on outcomes such as abundance, biomass, cover and species richness of vegetation were extracted together with metadata on site properties and other potential effect modifiers.

Results: Our searches identified more than 6,000 articles. After screening for relevance, 100 of them remained. Critical appraisal excluded 60 articles, leaving 40 articles with 41 independent studies. Almost two thirds of these studies had been conducted in Fennoscandia. Meta-analysis could be made of data from 31 of the studies. Overall, effects of reindeer on species richness of vascular plants depended on temperature, ranging from negative at low temperature to positive at high temperature. Effects on forbs, graminoids, woody species, and bryophytes were weak or non-significant, whereas the effect on lichens was negative. However, many individual studies showed clear positive or negative effects, but the available information was insufficient to explain this context dependence.

Conclusions: We see two pressing matters emerging from our study. First, there is a lack of research with which to build a circumpolar understanding of grazing effects, which calls for more studies using a common protocol to quantify reindeer impacts. Secondly, the highly context-dependent outcomes suggest that research and management have to consider local conditions. For instance, predictions of what a management decision would mean for the effects of reindeer on vegetation will have to take the variation of vegetation types and dominant growth forms, productivity, and grazing history into account. Policy and management have to go hand-in-hand with research in individual cases if the dynamics between plants, animals, and humans are to be sufficiently understood.

Keywords: Reindeer, Caribou, Rangifer tarandus, Forbs, Grasses, Graminoids, Woody species, Lichens, Bryophytes, Species diversity, Herbivory, Grazing, Browsing, Tundra

\footnotetext{
* Correspondence: claes.bernes@eviem.se

1 Mistra Council for Evidence-Based Environmental Management, Royal Swedish

Academy of Sciences, P.O. Box 50005, SE-104 05 Stockholm, Sweden

Full list of author information is available at the end of the article
} 


\section{Background}

\section{Reindeer and reindeer husbandry}

The reindeer (Rangifer tarandus L.) has a natural range extending over much of Eurasia's and North America's arctic, alpine and boreal zones. In considerable parts of this region, reindeer are the only large herbivores. In the 20th century, the species was also introduced into several areas where it never occurred naturally, including a number of islands in the Arctic and South Atlantic.

Rangifer tarandus is the only species of the genus Rangifer, but it includes several subspecies. The Eurasian subspecies are referred to as reindeer, while those native to North America generally are known as caribou. We will normally use the term caribou only when specifically referring to studies from North America.

Wild reindeer are still numerous in parts of the world, notably in Canada and Alaska. In northern Europe and Siberia, however, the majority of reindeer populations have been domesticated or semi-domesticated for several centuries. Here, they are herded by indigenous and local peoples. Some large populations of wild reindeer are still present in Russia, and a few small ones remain in southern Norway and southeastern Finland, but in Sweden all reindeer are semi-domesticated.

Over the seasons, many reindeer herds migrate over large distances between summer and winter pastures, and between pastures with different vegetation within the seasonal ranges. Reindeer in Sweden normally spend the snow-free season foraging on alpine tundra, in the forest-tundra ecotone, or in subalpine birch forests, whereas they spend the winter in boreal coniferous forests.
The quality of the summer ranges are very important for the growth and condition of the reindeer, including how well they can survive subsequent difficult winters. However, the quality of the winter pastures is usually a strong determining factor for the population size of reindeer [1]. During some winters, foraging is made difficult by ice or deep snow, and herd sizes can therefore vary considerably from one decade to another (although in some areas, domesticated reindeer may be given supplementary food through parts of the winter [2]). In Sweden, the number of reindeer has oscillated repeatedly between c. 150,000 and c. 300,000 over the last 125 years, with a long-term average of about 225,000 (see Figure 1). Similar numbers are currently found in Norway and Finland. These statistics refer to sizes of post-slaughter winter herds. In summer, the numbers are considerably higher due to calving during spring.

\section{Impacts of reindeer on arctic and alpine vegetation}

Being the most numerous large herbivores in circumpolar areas, reindeer play a pivotal role in their ecosystems. Through their effects on vegetation and carnivore populations, reindeer affect several ecosystem processes, while also providing essential ecosystem services to indigenous peoples [6].

The arctic and alpine tundra, where reindeer find much of their food, constitutes one of the most marginal habitats on earth [7]. For primary producers, conditions here are nutrient-limited and climatically extreme. The vegetation is dominated by growth forms that require only small amounts of nutrients (e.g. lichens and

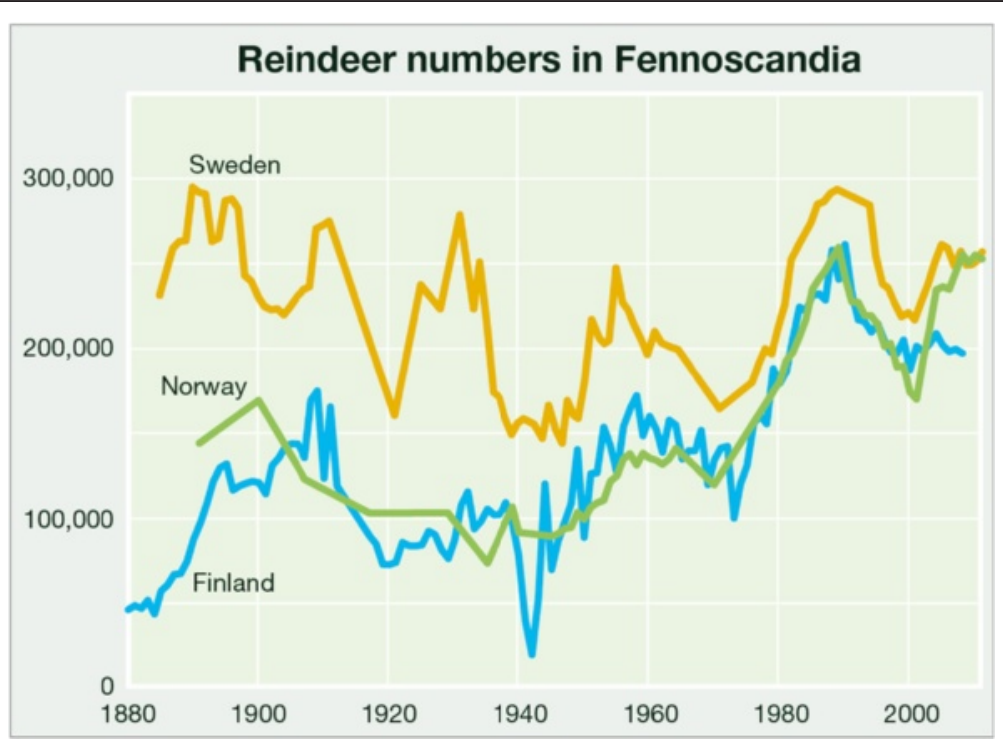

Figure 1 Reindeer numbers in Fennoscandia. The diagram shows total populations of semi-domesticated reindeer in Sweden, Norway and Finland following the autumn slaughter. After calving in spring, herds are significantly larger. Data from Statistics Sweden, Norwegian Directorate for Reindeer Husbandry, Finnish Reindeer Herder's Association, Finnish Game and Fisheries Research Institute (A. Ermala) and [3-5]. 
bryophytes) or are able to conserve nutrients (e.g. dwarf shrubs [8]).

Since reindeer are among the few herbivores able to digest lichens [9] and bryophytes [10], they are highly adapted to the vegetation of the tundra ecosystem [11]. Along with species of Cetraria, reindeer lichens (Cladonia and Cladina spp.) form a prominent part of the ground vegetation in many polar areas [12]. However, while lichens usually make up a substantial part of the reindeer diet, especially in winter, the animals may well survive without them if other food is available $[11,13]$. In summer, reindeer prefer vascular plants such as graminoids (grasses, sedges and rushes), forbs, and leaves of shrubs and deciduous trees. It is on summer pastures dominated by such plants that reindeer gain enough weight to survive the long winter, a season when icing events sometimes block their access to food resources almost entirely.

Reindeer can therefore be seen as seasonally adaptable ruminants and as intermediate feeders, and their migratory nature enables them to locate and utilise pulses of nutrients in space and time [14,15]. Nutrient pulses mainly occur after snowmelt, facilitating the growth of nutritious plants such as forbs and graminoids [16,17]. Reindeer are able to feed under spring-like conditions during large parts of the growing season, either by following snowmelt as it advances to higher altitudes or latitudes [18] or by changing preference during the summer season between growth forms with different phenological timing [19].

The impacts of reindeer herbivory can apparently be strong enough to cause transitions between vegetation states in tundra ecosystems [11], such as changes from lichen- to bryophyte- to graminoid-dominated vegetation. Shifts from lichen- to bryophyte-dominated stages following intensive grazing and trampling have been documented in a vast number of reindeer ranges $[6,11]$. Evidence for transitions to a graminoid-dominated state has been found in experimental studies of the effects of reindeer activity [20], or where reindeer behaviour has been manipulated, e.g. along fences regulating reindeer migration [21,22]. Yet, this evidence has not been corroborated by studies assessing rangelands of freely roaming semi-domesticated reindeer [23,24]. Some studies indicate that reindeer grazing (particularly by semidomesticated herds in Eurasia) may counteract climatically induced encroachment of trees and shrubs in tundra [6,25-27], even to the extent of limiting populations of shrub-dependent bird species [28]. However, others have found the impacts on vegetation by caribou in North America to be minor [14].

These seemingly inconsistent results may reflect the fact that Rangifer grazing systems are particularly variable, spanning vast areas with both domestic and wild herds, with introduced reindeer populations as well as native ones, with many different management systems, and with large climatic and biotic gradients. The response of vegetation to herbivory depends on factors such as productivity [29] and the long-term history of grazing [30], and these factors are known to vary considerably in areas where reindeer occur.

Changes in the impact of reindeer on vegetation currently cause concern in several regions, both where populations have been reduced and where they have reached historic highs [31,32]. For instance, increased population densities have reduced the abundance of palatable forage plants in some summer ranges, with consequences for reindeer calf weights [23]. Lack of forage has even been claimed to contribute to reindeer losses to predators [33] in areas where no assessment of reindeer impact on vegetation has been made. On the other hand, a reduction of the grazing pressure could have negative effects on biodiversity if it means that reindeer are no longer able to control shrub encroachment [34].

\section{Effects of climate change on vegetation and reindeer grazing}

Climate change will likely have strong effects on arctic ecosystems. Temperature changes occur at a much faster pace in the Arctic than in the world as a whole [35], causing a rapid increase in terrestrial biomass. This so-called 'greening of the Arctic' [6,36-38] involves both range expansions and increased in situ growth of tall shrubs, treeline trees and graminoids. The changes are not evenly distributed over the Arctic, however. Recent estimates [35,39] indicate substantial greening over about a third of the area (the North American High Arctic and the east European Arctic), browning within a few percent of the area, and no significant change within about half of the Arctic. The reasons for these differences vary, but they include differential warming, moisture changes, herbivory, industrial development and legacies from past land use [35].

The net effects of these changes on reindeer populations are not easy to predict [40]. Since plant species respond in different ways to climate change, novel ecosystems may arise [38]. The expansion of tall shrubs may have negative effects on field-layer plants due to competition, forage quality may change as plant phenology and nutrient cycling are altered [17], and reindeer migrations between summer and winter ranges may be affected. The effects of reindeer grazing on shrub expansion [27] might cause climatic feedbacks through albedo changes [41]. These could add to the highly dynamic nature of the tundra system. 


\section{Shifting perspectives on the impacts of reindeer grazing}

In Sweden, public opinion on how reindeer grazing affects mountain vegetation has shifted during the last few decades. In the 1990s, several well-publicised records of grazing-related vegetation degradation helped to form a widespread perception that some mountain areas were overutilised, and a concern that Swedish reindeer husbandry was not sustainable [42]. This was, for instance, reflected in a Swedish government bill stating that some areas had become overgrazed over a long time because of 'an imbalance between reindeer numbers and available forage' [43].

In other parts of Fennoscandia, severe overexploitation of reindeer ranges was noted, particularly on lichen heaths in Finnmark in northernmost Norway and in Finnish Lapland $[44,45]$, and on summer ranges dominated by vascular plants in Finnmark [23]. The damage on the lichen heaths was caused by a change in seasonal grazing from winter to summer, with lichens being worst affected due to their sensitivity to trampling during the snow-free season, whereas the reduction of palatable vascular plants was an effect of increased reindeer numbers.

More recently, however, the impact of reindeer grazing on mountain vegetation was subject to re-evaluation in Sweden. Analyses of available data on reindeer numbers and grazing effects indicated that the fears of overgrazing were based on local damage around a few enclosures and fences. Some of the effects were due to trampling on lichen-dominated vegetation, while others involved vegetation dominated by vascular plants, but no evidence of large-scale overutilisation of reindeer ranges in the Swedish mountains could be found [42]. The present-day consensus is that overgrazing of Swedish reindeer ranges has been temporary and local, and that it rarely has caused permanent damage. Recent evidence from Finnmark's winter rangelands points to the same conclusion [46]. Drawing on a literature review, Linkowski \& Lennartsson [47] concluded that even heavy grazing during a limited period can promote the diversity of alpine vegetation in the long run.

Moreover, the Swedish Parliament has adopted an environmental quality objective for the mountains. One of the specifications of this objective declares that it is essential to preserve 'a mountain landscape characterised by grazing' [48], referring to the conservation of key ecological functions in the landscape. However, no details have been given on how this specification is to be interpreted in ecological terms. For instance, one study suggests that grazing impacts on species richness are small, while effects on rare species and species composition (i.e. changes of relative species abundances) are stronger [49]. It is not clear how this translates into a 'landscape characterised by grazing'.

\section{Rationale for a systematic review}

The variation in the impacts of reindeer on vegetation between studies and regions demonstrates that it is challenging to predict the ecological consequences of various forms of management of both domesticated and wild reindeer populations. The lack of a comprehensive assessment of how vegetation is affected by reindeer suggests that there is a need to evaluate the ecological significance of reindeer grazing through a systematic review.

In Sweden especially, the recent re-evaluation of what reindeer grazing means for arctic and alpine vegetation is another reason why it is imperative to examine the scientific support for today's prevailing opinions on this issue. The need to interpret and clarify the environmental quality objective for the Swedish mountains also contributed to the decision to launch the present review.

In this review, we use a systematic approach to synthesise available evidence on the impacts of reindeer herbivory. Systematic reviews are designed to avoid bias and permit quantitative conclusions by means of metaanalysis. The ultimate aim of this review is to facilitate evidence-based management of reindeer grazing systems, with a particular focus on Fennoscandian conditions.

To the best of our knowledge, no systematic review of how reindeer grazing affects vegetation in treeless areas has been performed earlier. Our review was designed to include studies from any arctic or alpine region where reindeer are present, either as native or as introduced populations, provided that the data are informative for Fennoscandian conditions (e.g. by referring to vegetation types similar to those found in Fennoscandia). The review design was established in detail in an a priori protocol [50]. It follows the guidelines for systematic reviews issued by the Collaboration for Environmental Evidence [51].

\section{Stakeholder involvement}

This review was proposed by the Swedish Environmental Protection Agency. Prior to completion of the review protocol, a meeting was arranged with stakeholders with an interest in reindeer husbandry and environmental aspects of reindeer herbivory in Sweden [50]. Several suggestions made by the stakeholders were adopted by the review team, e.g. that the review should not be restricted to impacts on biodiversity but should consider other aspects of vegetation too, and that it should include vegetation in subalpine birch forests as well as treeless mountain areas. We have thus covered studies on treelines and on the forest-tundra ecotone, including subalpine birch forests but not coniferous forests at lower elevations. Moreover, it was pointed out that overgrazing of reindeer pastures is a questionable concept. Being 
perspective-driven, its definition tends to vary between stakeholders [52], and no attempt to define or apply the concept of overgrazing has been made in this review.

Before submission, peer review, revision and final publication of the protocol, a draft version was open for public review at the EviEM website in November 2012. Comments were received from about ten stakeholders, most of them Swedish scientists or environmental managers.

\section{Objective of the review}

The primary aim of this review is to clarify how grazing, browsing and trampling by reindeer (or caribou) affect the vegetation of arctic, subarctic, alpine and subalpine areas, including the forest-tundra ecotone. We would like to point out that an understanding of the reasons behind variations in reindeer grazing pressure on vegetation is outside the scope of this review. Such an understanding would, for instance, require analyses of the entire annual range of the grazing system, including the use of winter pastures in the boreal forest, variations in reindeer management, historical land use, external pressures from other land users, and political, legal, and societal drivers. This was not possible to achieve within the time, resource, and data constraints of our review.

\section{Primary question}

What are the impacts of reindeer/caribou (Rangifer tarandus $L$.) on arctic and alpine vegetation?

\section{Components of the primary question:}

- Subject (population): Vegetation (as a whole, or divided into major groups such as graminoids, forbs, dwarf-shrubs, lichens, mosses etc.) in alpine/subalpine areas or arctic/subarctic tundra, including the forest-tundra ecotone.

- Exposure: Herbivory (including grazing, browsing and trampling) by reindeer (or caribou). Reindeer density (number of reindeer per unit area) is used as a quantification of the intensity of herbivory.

- Comparator: Lower (or no) herbivory by reindeer (or caribou).

- Outcome: Change of vegetation. Relevant aspects of vegetation include cover (abundance), biomass, diversity (e.g. species richness), structure, composition (at both species and functional group levels) and productivity.

\section{Methods}

\section{Searches for literature}

Searches for relevant literature have been made using online publication databases, search engines, specialist websites and bibliographies of literature reviews. As far as possible, the search strings specified below were applied throughout the searches using online databases, search engines and specialist websites. In several cases, though, they had to be simplified as some sites can handle only a very limited number of search terms or do not allow the use of 'wildcards' or Boolean operators.

Full details of the search strings used and the number of articles found at each stage of the search are provided in Additional file 1.

\section{Search terms}

A scoping exercise identified the following search terms as being most closely related to the primary question:

Exposure: herbivory, graz", brows", trampl"

Agent: reindeer, caribou, Rangifer

The terms within each category ('exposure' and 'agent') were combined using the Boolean operator 'OR'. The two categories were then combined using the Boolean operator 'AND'. An asterisk (*) indicates wildcard truncation.

Searches were also made for Swedish, Norwegian, Finnish and Russian counterparts of the above terms. The following search strings were used:

- English: (herbivory OR graz* OR brows* OR trampl") AND (reindeer OR caribou OR Rangifer)

- Swedish: renbet* OR ((herbivori OR bet* OR tramp*) AND (renar OR caribou OR Rangifer))

- Norwegian: reinbeit* OR renbeit* OR ((beit* OR gressing OR tramp") AND ("rein OR "ren OR reinsdyr OR rensdyr OR karibu OR caribou OR Rangifer))

- Finnish: (laidun* OR tallata OR talloa OR polkea) AND (poro OR Rangifer)

- Russian: (пастбище OR пастись OR выпасать OR выбирать OR высматривать OR вытаптывать) AND (олень OR оленеводство)

No time, language or document type restrictions were applied.

In addition to the exposure and agent terms mentioned above, the following terms for 'subject' had been tested during the scoping exercise:

vegetation, vascular, plant*, herb*, forb*, gramin*, lichen ${ }^{*}$, moss", bryophyte $^{*}$, flora, shrub*, tree*, forage, tundra, alpine, subalpine, arctic, subarctic, heath", pasture*, rangeland*

However, it was found that searches using the exposure and agent terms alone were specific enough to return a fully manageable amount of articles. Including the above subject terms would have restricted the search 
and reduced the number of hits by a factor of about two. The subject terms were therefore excluded - the loss of specificity was judged to be less important than the increase of sensitivity.

\section{Publication databases}

The search included the following online publication databases:
1) Academic Search Premier
2) Agricola
3) Arctic \& Antarctic Regions (EBSCOhost)
4) Arto (reference database of Finnish articles)
5) Biological Abstracts
6) BioOne
7) COPAC
8) Directory of Open-Access Journals
9) GEOBASE and GeoRef (Engineering Village)
10) IngentaConnect
11) JSTOR
12) Melinda (union catalogue of Finnish libraries)
13) Scopus
14) SpringerLink
15) SwePub (academic publications at Swedish universities)
16) Web of Science
17) Wiley Online Library

To identify relevant literature in bibliographic databases, systematic reviews normally use searches in titles, abstracts and keywords of the indexed publications [51]. To an increasing extent, however, such databases now also allow searches in the full text of available articles. For the purpose of checking whether full-text searching identifies relevant articles more efficiently and/or completely than conventional searching, we made both kinds of searches in three of the databases (Academic Search Premier, JSTOR and Scopus). The other fourteen databases were searched at title/abstract/keyword level only.

\section{Search engines}

An Internet search was also performed using the following search engines:

\section{Google (www.google.com) \\ Google Scholar (scholar.google.com) \\ Dogpile (www.dogpile.com) \\ Scirus (www.scirus.com)}

In each case, the first 100 hits (based on relevance) were examined for appropriate data. Potentially useful documents that had not already been found in publication databases were recorded.

\section{Specialist websites}

Websites of the specialist organisations listed below were searched for links or references to relevant publications and data, including grey literature. Potentially useful documents that had not already been found using publication databases or search engines were recorded.

Alaska Department of Natural Resources (dnr.alaska. gov)

Alberta Conservation Association

(www.ab-conservation.com)

Alberta Reindeer Association

(www.albertareindeer.com)

Arctic Centre (University of Lapland)

(www.arcticcentre.org)

Arctic Council (www.arctic-council.org)

Bioforsk (www.bioforsk.no)

Bureau of Land Management, US Dept. of the Interior (www.blm.gov)

Conservation of Arctic Flora and Fauna (CAFF)

(www.caff.is)

Environment Canada (www.ec.gc.ca)

European Commission Joint Research Centre (ec. europa.eu/dgs/jrc)

European Environment Agency (www.eea.europa.eu)

Finland's environmental administration

(www.environment.fi)

Finnish Environment Institute (SYKE)

(www.environment.fi)

Finnish Game and Fisheries Research Institute

(www.rktl.fi)

Food and Agriculture Organization of the United

Nations (www.fao.org)

Greenland Institute of Natural Resources

(www.natur.gl)

GRID Arendal (www.grida.no)

International Centre for Reindeer Husbandry (icr. arcticportal.org)

International Union for Conservation of Nature

(www.iucn.org)

Ministry of Natural Resources of the Russian

Federation (www.mnr.gov.ru)

Natural Resources Canada (www.nrcan.gc.ca)

Nordic Council for Reindeer Husbandry Research

(Rangifer journal) (site.uit.no/rangifer)

Nordic Council of Ministers (www.norden.org)

Northern Research Institute (NORUT) (www.norut.no)

Norwegian Directorate for Nature Management

(www.dirnat.no)

Norwegian Institute for Nature Research (NINA)

(www.nina.no)

Norwegian Polar Institute (www.npolar.no)

Norwegian Wild Reindeer Centre (www.villrein.no)

Reindeer Herders' Association (www.paliskunnat.fi) 
Reindeer Research Program, University of Alaska

(reindeer.salrm.uaf.edu)

Reindriftsforvaltningen (www.reindrift.no)

Reinportalen (www.reinportalen.no)

Russian Guild of Ecologists (www.ecoguild.ru)

Russian Regional Environmental Centre

(www.rusrec.ru)

Sámediggi (Finnish Sami Parliament)

(www.samediggi.fi)

Sámediggi (Norwegian Sami Parliament)

(www.sametinget.no)

Sámi Reindeer Herders' Association of Finland

(www.beboedu.fi)

Sápmi (Sami Parliament in Sweden)

(www.eng.samer.se)

Swedish Environmental Protection Agency

(www.naturvardsverket.se)

Swedish University of Agricultural Sciences (SLU)

(www.slu.se)

United Nations Environment Programme

(www.unep.org)

United States Environmental Protection Agency

(www.epa.gov)

United States Fish and Wildlife Service (www.fws.gov)

University of Alaska Anchorage (www.uaa.alaska.edu)

\section{Other literature searches}

Relevant literature was also searched for in bibliographies of literature reviews by Forbes \& Kumpula [31], Moen \& Danell [42], Linkowski \& Lennartsson [47] and Suominen \& Olofsson [53]. Potentially useful documents that had not already been found in online sources were recorded. A few more articles were brought to our attention by stakeholders.

\section{Search update}

An update to the literature searches was made one year after the main searches. The update involved searches for articles in English using a subset of the publication databases and search engines listed above (see Additional file 1).

\section{Screening}

\section{Screening process}

Articles found by searches in publication databases were evaluated for inclusion at two or three successive levels. The literature identified by full-text searches in three databases was first assessed by title by a single reviewer (CB). In cases of uncertainty, the reviewer chose inclusion rather than exclusion.

The articles found to be relevant based on title were then combined with those identified by title/abstract/ keyword searches in the fourteen other publication databases. After removal of duplicates, these articles were assessed by abstract, again by a single reviewer (CB) who in cases of uncertainty tended towards inclusion.

A second reviewer (JS) assessed a subset consisting of $20 \%$ of the abstracts, and the agreement between the two reviewers' assessments was checked with a kappa test. The outcome, $\mathrm{K}=0.565$, indicated a 'moderate' agreement [54], but since the inconsistency had almost entirely been caused by the main reviewer being more inclusive than the second one, it seemed safe to proceed with the screening without modification or further specification of the inclusion/exclusion criteria.

Next, each article found to be relevant on the basis of abstract was judged for inclusion by a reviewer studying the full text. This task was shared by all members of the review team. The articles were randomly distributed within the team, but some redistribution was then made to avoid having reviewers assess studies authored by themselves or written in an unfamiliar language. Studies found by other means than database searches were also entered at this stage in the screening process. Doubtful cases - articles that the reviewer could not include or exclude with certainty even after having read the full text - were discussed and decided on by the entire team.

A list of all studies rejected on the basis of full-text assessment is provided in Additional file 2 together with the reasons for exclusion. This file also contains a list of articles that we failed to find in full text.

\section{Study inclusion criteria}

Each study had to pass each of the following criteria in order to be included at any of the screening stages:

- Relevant subject(s): Vegetation in alpine/subalpine areas or arctic/subarctic tundra, including the forest-tundra ecotone. Reindeer may also occur in boreal coniferous forests, but studies of vegetation in such regions were not included; nor were studies of reindeer herbivory on meadows formerly used for cattle or sheep grazing.

- Relevant types of exposure: Grazing, browsing or trampling by reindeer. Modern reindeer husbandry may also affect vegetation through disturbances caused by reindeer herders' all-terrain vehicles, but such impacts are not considered by this review.

- Relevant types of comparator: Lower or no grazing, browsing or trampling.

- Relevant types of outcome: Change in cover, abundance, biomass, diversity (including species richness), structure, composition or productivity of vegetation. Studies of single plant species and of the soil seed bank were also included.

- Relevant types of study: Any primary field study comparing vegetation in areas and/or time periods with different degrees of reindeer herbivory. 
Remote-sensing studies have been included, but not simulation-modelling studies or field studies of simulated herbivory, since these do not represent direct impacts of reindeer.

The review protocol indicated that manipulative studies as well as purely observational ones were to be considered. However, while we have included experiments where fences were used to keep reindeer out from certain areas, we have chosen to exclude studies involving artificial removal or transplantation of vegetation, again in order to focus on effects of reindeer herbivory under natural conditions. We have also excluded studies where differences in grazing pressure have been inferred from vegetation properties, since such conclusions would introduce circular reasoning if used in this review.

At screening on full text, the following inclusion criterion was also applied:

- Language: Full text written in English, Swedish, Norwegian, Danish, Finnish, German or Russian.

\section{Potential effect modifiers and reasons for heterogeneity}

The following potential effect modifiers were considered and recorded:

Latitude and longitude
Elevation
Annual mean temperature
Annual mean precipitation
Soil moisture (dry/mesic/wet)
Soil/bedrock type
Vegetation type
Reindeer subspecies involved
Seasonality of reindeer grazing
Domestication status of the reindeer
Presence and species identity of other herbivores
Control for small herbivores (using small-mesh
exclosures)
History of herd (e.g. whether native or introduced)
Study design and experimental treatment
Study and intervention timescale and seasonality

\section{Study quality assessment}

Articles that remained included after full-text screening were subject to critical appraisal as described below. This appraisal was made by the four ecologists in the review team (KAB, BF, JM, JS) and double-checked by the fifth member of the team (CB). Uncertain cases were discussed and decided on by the entire team.

Before critical appraisal, the articles had been redistributed among the reviewers based on where the studies had been carried out. All studies from a specific region were assessed by the same reviewer, which made it easier to detect any redundancies between them.

Articles sorted under the categories listed below were considered to have high susceptibility to bias and were therefore excluded from the review.

- Methodology inadequately described.

- Inappropriate comparator (comparison between different seasons, use of small-mesh exclosures that prevented grazing by small mammals as well as reindeer, or comparator difficult to interpret for the purposes of this review). Studies that compare grazing in different seasons have usually been made in areas where summer and winter ranges are separated by a fence. Since the effects of grazing on bare and snow-covered ground are entirely different, such a study design makes it difficult to judge which of the two ranges that is more heavily grazed, even if reindeer densities are known in both of them.

- No replication at lowest level (no replication of exclosures or site comparators). Studies based on comparison of so-called reindeer-herding districts or regions have not been excluded, however, even though study units representing such a district may be seen as pseudoreplicates in a strict statistical sense. Since the study units represent different geographical contexts within the district and thus also differ in terms of biology and reindeer impact, the interpretation of them as pseudoreplicates is not justified in an ecological sense.

- No data on variability.

- Vegetation data difficult to interpret (such as when methods used to assess vegetation have differed between sites or sampling seasons).

- Reindeer data difficult to interpret (such as when conclusions on the presence of reindeer have been based on weak and circumstantial evidence).

Since checks for redundancy were made during critical appraisal, this was added as a cause for exclusion, although it is not strictly a quality criterion:

- Primary data redundant (data also published elsewhere).

In accordance with the review protocol, notes were also made on certain other quality aspects (such as whether plot locations were randomised and well-matched or not), but since these aspects were considered less important than those listed above, they were not chosen as exclusion criteria. The duration of exposure differences (i.e. how long differences of grazing pressure had been maintained) was recorded too, but it was handled as a potential effect modifier rather than a measure of study quality. 
According to the review protocol, studies were to be categorised as having high, medium, or low susceptibility to bias based on the critical appraisal. However, since we adopted fairly strict exclusion criteria, there seemed to be no need for a further quality grading of studies that fulfilled quality standards well enough to remain included.

A list of the studies that were rejected due to high susceptibility to bias is provided in Additional file 2 together with the reasons for exclusion.

\section{Data extraction strategy}

Outcome means and measures of variation (standard deviation, standard error, confidence intervals) have been extracted from tables and graphs in the included articles, using image analysis software when necessary (software used included Graphclick for Mac, http://www.arizonasoftware.ch/graphclick/, and WebPlotDigitizer, http:// arohatgi.info/WebPlotDigitizer/). Data were extracted not only on major functional or taxonomic groups of vegetation and on vegetation as a whole, but also on individual species and genera whenever such information was available.

Most studies in this field compare vegetation in areas that for a long time have been subject to different levels of reindeer herbivory, or vegetation inside and outside areas that have been fenced to exclude reindeer. Thus, they are usually 'CI' (Comparator/Intervention) studies describing effects of reindeer herbivory relative to a control site. Other studies have a 'BA' (Before/After) design - they present data on vegetation before and after reindeer exclusion or over a period when herbivory has changed. A few studies combine these two approaches in 'BACI' (Before/After/Comparator/Intervention) designs, where site control and intervention comparisons are made both before and after herbivory has changed.

Where time-series of data were available, we only extracted the most recent results (plus pre-intervention data from BA and BACI studies). Similarly, we only extracted data from sites under high and low grazing pressure even if data from sites under intermediate pressure were also available.

In a few cases, study authors have been asked to supply vegetation data in digital format. This was done where useful data had been published in graphs from which they were difficult to extract accurately enough, or when it was known or assumed that considerable amounts of relevant but unpublished data could be available in addition to the published results. In cases where raw data were received, summary statistics have been calculated by us. This has e.g. enabled us to consider data on the diversity of vegetation even from studies where the published outcomes only include biomass or abundance.
Data on potential effect modifiers and other metadata were extracted from the included articles whenever available, but climatic data were downloaded from the WorldClim database [55].

Data on reindeer densities are often incomplete or entirely absent in studies of the effects of reindeer grazing. Many of these studies simply describe sampling sites as being subject to 'grazing' or 'no (or lighter) grazing'. Some authors have actually estimated local reindeer densities, using counts of animals, trampling indicators or counts of reindeer droppings, but the two latter types of data cannot readily be transformed to reindeer numbers per unit area.

In the absence of reliable local information, therefore, we have used data on average reindeer densities at a regional level (e.g. mean densities in entire reindeerherding districts). Where such data were not provided by study authors, we have calculated them ourselves for the appropriate time periods using herd sizes and range sizes retrieved from external sources, such as Reindriftsforvaltningen (the Norwegian reindeer herding administration) and Svensk-norska renbeteskommissionen (the Swedish-Norwegian commission on reindeer pastures). We are well aware that these data must be used and interpreted with care, since herding districts may cover thousands of square kilometres and a study site may be far from representative of average conditions in the district where it is located.

The extraction of data was carried out by the four ecologists in the review team and then double-checked by the fifth team member. Each pair of BA or CI outcomes (and each quadruple of BACI outcomes) was recorded in a separate row of an Excel spreadsheet together with data on reindeer densities and all appropriate metadata, including data on effect modifiers.

\section{Data synthesis and presentation}

The impacts of reindeer exposure on vegetation were analysed using meta-analytical approaches. Metaanalyses were carried out using the metafor package [56] within the $\mathrm{R}$ environment v. 3.0.2 [57]. Standardised mean difference (SMD) effect sizes were derived for all responses using Hedges' $g$ statistic. The effect sizes were calculated as the difference between the mean response at high exposure to reindeer and the mean response at low exposure to reindeer divided by the pooled standard deviation. Positive effect sizes thus indicate that the response parameter was higher at high reindeer exposure than at low exposure.

We calculated summary effect sizes by using random effects models. Models were developed for the main groups of vegetation (lichens, bryophytes, forbs/herbs, graminoids and woody plants) and the most common aspects of vegetation assessed (cover, abundance, 
biomass, height and productivity) as well as for bareground cover and species richness of vascular and non-vascular plants. Where applicable, subgroup models were developed for further vegetation groups within each of the main groups (e.g. for deciduous and evergreen shrubs). Heterogeneity was estimated by the Hedges' method, and data are presented in forest plots showing mean effect sizes and $95 \%$ confidence intervals. Models were weighted by the inverse of the variance.

We used univariate mixed effects models in order to test whether the impact of reindeer exposure on vegetation varied with reindeer density, vegetation cover or mean annual temperature. The independent variables were fitted as modifiers in the meta-analytical models. Four separate measures of reindeer density were used: (1) the high-exposure reindeer density, (2) the absolute difference in reindeer density between high and low exposures, (3) the relative difference in reindeer density $(100 \times$ [high density - low density] / high density $)$ and (4) the accumulated exposure difference estimated as the absolute difference in reindeer density multiplied by the duration of the exposure difference. We investigated whether the impact of reindeer exposure varied with the cover of lichens and bare ground only, as there was not enough data to do this for other vegetation groups. Lichen and bare-ground cover effect sizes were fitted against the average cover of lichens and bare ground (meaning that the standardised mean difference in lichen cover was used as the dependent variable and the average lichen cover across both exposures as the independent variable).

\section{Results}

\section{Review descriptive statistics}

\section{Searches, screening and quality assessment}

The main searches for literature were conducted between 19 October and 8 December 2012, and an update was made on 2 November 2013.

Full-text searches with English search terms in three publication databases (Academic Search Premier, JSTOR and Scopus) returned a total of 8,039 articles (6,638 after removal of duplicates). After title screening of these articles, 618 of them remained. Searches based on title/abstract/keywords in fourteen other databases returned a total of 1,323 articles (772 after removal of duplicates). Removal of the overlap between the outcomes of the two different search approaches left a total of 1,197 unique publications. After screening based on the abstracts of these articles, 376 of them remained. About two thirds of the exclusions were due to absence of relevant vegetation data.

Searches using search engines returned 9 potentially relevant articles (8 found with English search terms, 1 with Norwegian ones) in addition to those that already had been identified. Similarly, searches on specialist websites located another 9 potentially useful publications (7 were found using English search terms and 2 using Norwegian ones). An additional 15 potentially relevant articles were found in bibliographies of literature reviews, while 6 more were added following contacts with stakeholders.

This resulted in a total of 415 articles to be screened on a full-text basis. After screening, 96 of them were still included. At this stage, the most common reasons for exclusion were that studies dealt with other aspects of reindeer than their herbivory, that no relevant vegetation data were reported, or that no primary observational data were presented at all. In 28 cases, publications had to be excluded because they were not found in full text.

When the search was updated in 2013, 6 new potentially relevant articles were found, 4 of which were included after screening on full text.

Finally, quality assessment was made of the 100 articles that had passed the screening process, and 60 of them were then excluded. Common reasons for exclusion were inadequate methodological descriptions, and vegetation or reindeer data that were difficult to interpret. In 12 cases, articles were excluded since they reported data that could also be found elsewhere.

The 40 finally included articles are listed in Table 1. Since one of them (van der Wal \& Brooker [20]) reports on three different studies, two of which were found to be useful in this review, the total number of included studies is 41. See Figure 2 and Additional file 3 for further details on search results and outcomes of the screening process and quality assessment.

\section{Sources of included articles}

Nearly all of the 40 articles included in this review were found in publication databases. Of the 39 included publications that had been identified during the main searches in late 2012, 37 were returned by at least one of the databases searched (see Additional file 4).

The three publication databases where full-text searches had been made were also searched based on title/abstract/keywords. Of the 37 included articles found in 2012, 34 were retrieved by at least one of the full-text searches, whereas 33 were found by at least one of the searches on title/abstract/keywords in the same three databases. The single included study caught by the former searches but not by the latter ones was a remote-sensing analysis of vegetation in reindeer-herding districts [58] where 'grazing' was mentioned in the full text but not in the abstract. In general, the articles found by full-text searches but not by title/abstract/keywords searches had little or no relevance to the topic of this review. Since the full-text searches required about a week of extra work, mainly spent screening more than 6,000 titles and 
Table 1 Articles included in the systematic review

\begin{tabular}{|c|c|c|c|c|}
\hline Authors & Year & Title & Study area & Ref. \\
\hline Bråthen \& Oksanen & 2001 & Reindeer reduce biomass of preferred plant species & N Norway & [73] \\
\hline Bråthen et al. & 2007 & Induced shift in ecosystem productivity? Extensive scale effects of abundant large herbivores & N Norway & [23] \\
\hline Cahoon et al. & 2012 & $\begin{array}{l}\text { Large herbivores limit } \mathrm{CO}_{2} \text { uptake and suppress carbon cycle responses to warming in West } \\
\text { Greenland }\end{array}$ & Greenland & {$[68$} \\
\hline den Herder et al. & 2004 & Effects of reindeer browsing on tundra willow and its associated insect herbivores & Finland & {$[74]$} \\
\hline Dormann \& Skarpe & 2002 & $\begin{array}{l}\text { Flowering, growth and defence in the two sexes: Consequences of herbivore exclusion for } \\
\text { Salix polaris }\end{array}$ & Svalbard & {$[75]$} \\
\hline Eriksson et al. & 2007 & Use and abuse of reindeer range & Sweden & {$[6$} \\
\hline Eskelinen \& Oksanen & 2006 & $\begin{array}{l}\text { Changes in the abundance, composition and species richness of mountain vegetation in } \\
\text { relation to summer grazing by reindeer }\end{array}$ & Finland & {$[76]$} \\
\hline Gaare et al. & 2006 & Overvåking av vinterbeiter i Vest-Finnmark og Karasjok: Ny beskrivelse av fastrutene & N Norway & {$[59$} \\
\hline Gonzalez et al. & 2010 & Large-scale grazing history effects on Arctic-alpine germinable seed banks & N Norway & {$[69$} \\
\hline Gough et al. & 2008 & $\begin{array}{l}\text { Long-term mammalian herbivory and nutrient addition alter lichen community structure in } \\
\text { Alaskan dry heath tundra }\end{array}$ & Alaska, USA & {$[77$} \\
\hline Grellmann & 2002 & Plant responses to fertilization and exclusion of grazers on an arctic tundra heath & N Norway & {$[78$} \\
\hline Hansen et al. & 2007 & Ungulate impact on vegetation in a two-level trophic system & Svalbard & {$[61$} \\
\hline Jandt et al. & 2003 & Western Arctic Caribou Herd winter habitat monitoring and utilization, 1995-1996 & Alaska, USA & {$[60$} \\
\hline Johansen \& Karlsen & 2005 & $\begin{array}{l}\text { Monitoring vegetation changes on Finnmarksvidda, Northern Norway, using Landsat MSS } \\
\text { and Landsat TM / ETM+ satellite images }\end{array}$ & N Norway & {$[58$} \\
\hline Kitti et al. & 2009 & Long- and short-term effects of reindeer grazing on tundra wetland vegetation & $\begin{array}{l}\text { N Norway/ } \\
\text { Finland }\end{array}$ & {$[66$} \\
\hline Lehtonen \& Heikkinen & 1995 & $\begin{array}{l}\text { On the recovery of mountain birch after Epirrita damage in Finnish Lapland, with a particular } \\
\text { emphasis on reindeer grazing }\end{array}$ & Finland & {$[7$} \\
\hline Manseau et al. & 1996 & $\begin{array}{l}\text { Effects of summer grazing by caribou on composition and productivity of vegetation: } \\
\text { Community and landscape level }\end{array}$ & Canada & {$[8$} \\
\hline Moen et al. & 2009 & $\begin{array}{l}\text { Variations in mountain vegetation use by reindeer (Rangifer tarandus) affects dry heath but } \\
\text { not grass heath }\end{array}$ & Sweden & [63] \\
\hline Nellemann et al. & 2000 & $\begin{array}{l}\text { Cumulative impacts of tourist resorts on wild reindeer (Rangifer tarandus tarandus) during } \\
\text { winter }\end{array}$ & S Norway & {$[81$} \\
\hline Nellemann et al. & 2001 & Winter distribution of wild reindeer in relation to power lines, roads and resorts & S Norway & {$[82$} \\
\hline Olofsson \& Strengbom & 2000 & Response of galling invertebrates on Salix lanata to reindeer herbivory & N Norway & {$[8$} \\
\hline Olofsson et al. & 2001 & $\begin{array}{l}\text { Effects of summer grazing by reindeer on composition of vegetation, productivity and } \\
\text { nitrogen cycling }\end{array}$ & $\begin{array}{l}\text { N Norway/ } \\
\text { Finland }\end{array}$ & {$[21$} \\
\hline Olofsson et al. & 2004 & $\begin{array}{l}\text { Importance of large and small mammalian herbivores for the plant community structure in } \\
\text { the forest tundra ecotone }\end{array}$ & $\begin{array}{l}\text { N Norway/ } \\
\text { Sweden }\end{array}$ & {$[84$} \\
\hline Olofsson \& Oksanen & 2005 & Effects of reindeer density on vascular plant diversity on North Scandinavian mountains & $\begin{array}{l}\text { N Norway/ } \\
\text { Finland/Sweden }\end{array}$ & {$[49$} \\
\hline Olofsson & 2006 & $\begin{array}{l}\text { Short- and long-term effects of changes in reindeer grazing pressure on tundra heath } \\
\text { vegetation }\end{array}$ & N Norway & {$[6$} \\
\hline Olofsson et al. & 2009 & Herbivores inhibit climate-driven shrub expansion on the tundra & $\begin{array}{l}\text { N Norway/ } \\
\text { Sweden }\end{array}$ & {$[\angle$} \\
\hline Olofsson et al. & 2013 & Complex biotic interactions drive longterm vegetation dynamics in a subarctic ecosystem & Sweden & {$[85$} \\
\hline Pajunen & 2009 & $\begin{array}{l}\text { Environmental and biotic determinants of growth and height of arctic willow shrubs along a } \\
\text { latitudinal gradient }\end{array}$ & Yamal, Russia & {$[8$} \\
\hline Pedersen \& Post & 2008 & $\begin{array}{l}\text { Interactions between herbivory and warming in aboveground biomass production of arctic } \\
\text { vegetation }\end{array}$ & Greenland & {$[8$} \\
\hline Post \& Pedersen & 2008 & Opposing plant community responses to warming with and without herbivores & Greenland & {$[70$} \\
\hline Post & 2013 & Erosion of community diversity and stability by herbivore removal under warming & Greenland & {$[8$} \\
\hline Ravolainen et al. & 2010 & $\begin{array}{l}\text { Additive partitioning of diversity reveals no scale-dependent impacts of large ungulates on } \\
\text { the structure of tundra plant communities }\end{array}$ & N Norway & [2 \\
\hline
\end{tabular}


Table 1 Articles included in the systematic review (Continued)

\begin{tabular}{|c|c|c|c|c|}
\hline Ravolainen et al. & 2011 & $\begin{array}{l}\text { Rapid, landscape scale responses in riparian tundra vegetation to exclusion of small and large } \\
\text { mammalian herbivores }\end{array}$ & N Norway & [64] \\
\hline Tømmervik et al. & 2009 & $\begin{array}{l}\text { Above ground biomass changes in the mountain birch forests and mountain heaths of } \\
\text { Finnmarksvidda, northern Norway, in the period 1957-2006 }\end{array}$ & N Norway & [89] \\
\hline Tømmervik et al. & 2012 & $\begin{array}{l}\text { Rapid recovery of recently overexploited winter grazing pastures for reindeer in northern } \\
\text { Norway }\end{array}$ & N Norway & {$[46$} \\
\hline van der Wal et al. & 2001 & Differential effects of reindeer on high Arctic lichens & Svalbard & [90] \\
\hline van der Wal \& Brooker & 2004 & Mosses mediate grazer impacts on grass abundance in arctic ecosystems & Svalbard & [20] \\
\hline Vistnes et al. & 2004 & Effects of infrastructure on migration and range use of wild reindeer & S Norway & [91] \\
\hline Zamin \& Grogan & 2012 & $\begin{array}{l}\text { Birch shrub growth in the low Arctic: The relative importance of experimental warming, } \\
\text { enhanced nutrient availability, snow depth and caribou exclusion }\end{array}$ & Canada & ГC \\
\hline Zamin \& Grogan & 2013 & $\begin{array}{l}\text { Caribou exclusion during a population low increases deciduous and evergreen shrub species } \\
\text { biomass and nitrogen pools in low Arctic tundra }\end{array}$ & Canada & \\
\hline
\end{tabular}

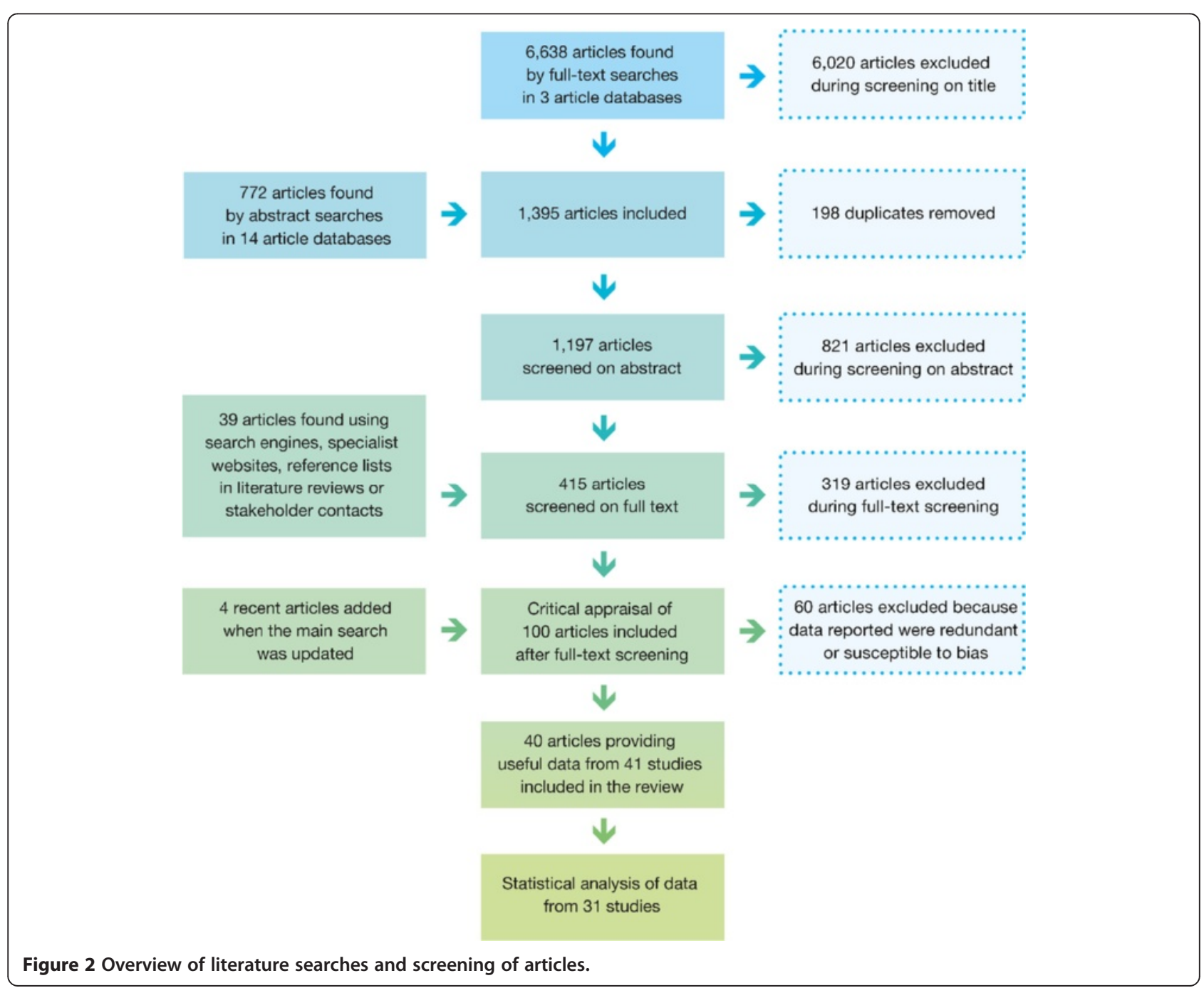


some 400 abstracts, we conclude in retrospect that this effort did not pay off well enough to be justified.

The two included publications that had not been retrieved from any of the databases, Gaare et al. [59] and Jandt et al. [60], were found at specialist websites belonging to the Norwegian Institute for Nature Research and the Bureau of Land Management of the US Dept. of the Interior, respectively. The report by Gaare et al. [59] is the only included one that is written in a non-English language (Norwegian), and even this one was found using English search terms.

The searches that used non-English search strings returned very few potentially relevant publications that had not already been identified by other means. A total of about 30 articles in Swedish, Danish, Norwegian or Finnish were considered during the initial stages of this review, but a majority of them had been found in review bibliographies or through searches with English search terms, and none of them made it through both full-text screening and critical appraisal, with the one exception mentioned above.

While the articles screened on full text included several publications dating from the 1980s or earlier, a large share of the older articles were excluded during this stage of screening or during critical appraisal (see Figure 3). All but two of the 40 articles finally included were published in 2000 or later.

\section{Overall characteristics of included studies}

Although the searching and screening processes involved no geographical limitations, 25 of the 41 included studies were conducted in Fennoscandia (see Figures 4, 5 and 6). The other ones were carried out in Svalbard, Greenland, Canada, Alaska or Russia. Most of the studies (31 of them) were conducted in treeless terrain such as tundra or alpine areas, but 2 studies were carried out in subalpine birch forests, and 8 studies reported data from both treeless areas and birch forests.

As a consequence of the uneven geographic distribution of the studies, the majority (26 of them) dealt with herbivory by native Eurasian reindeer (Rangifer tarandus tarandus), either semi-domesticated or wild. The North American studies were all concerned with wild caribou (R. t. caribou or R. t. groenlandicus). The reindeer on Svalbard (R. t. platyrhynchus) are wild and native to the archipelago, but one of the studies conducted there (Hansen et al. [61]) was made on the Brøggerhalvøya peninsula, where Svalbard reindeer were reintroduced in 1978 after a century of absence.

About half of the studies (21 of them) were made in areas where reindeer herbivory mainly took place during summer, whereas winter grazing was the subject of 5 studies. In 13 cases, reindeer were present during several seasons or throughout the whole year. Note that the winter grazing considered in this review was confined to treeless areas and birch forests, as studies in coniferous forests were outside our scope.

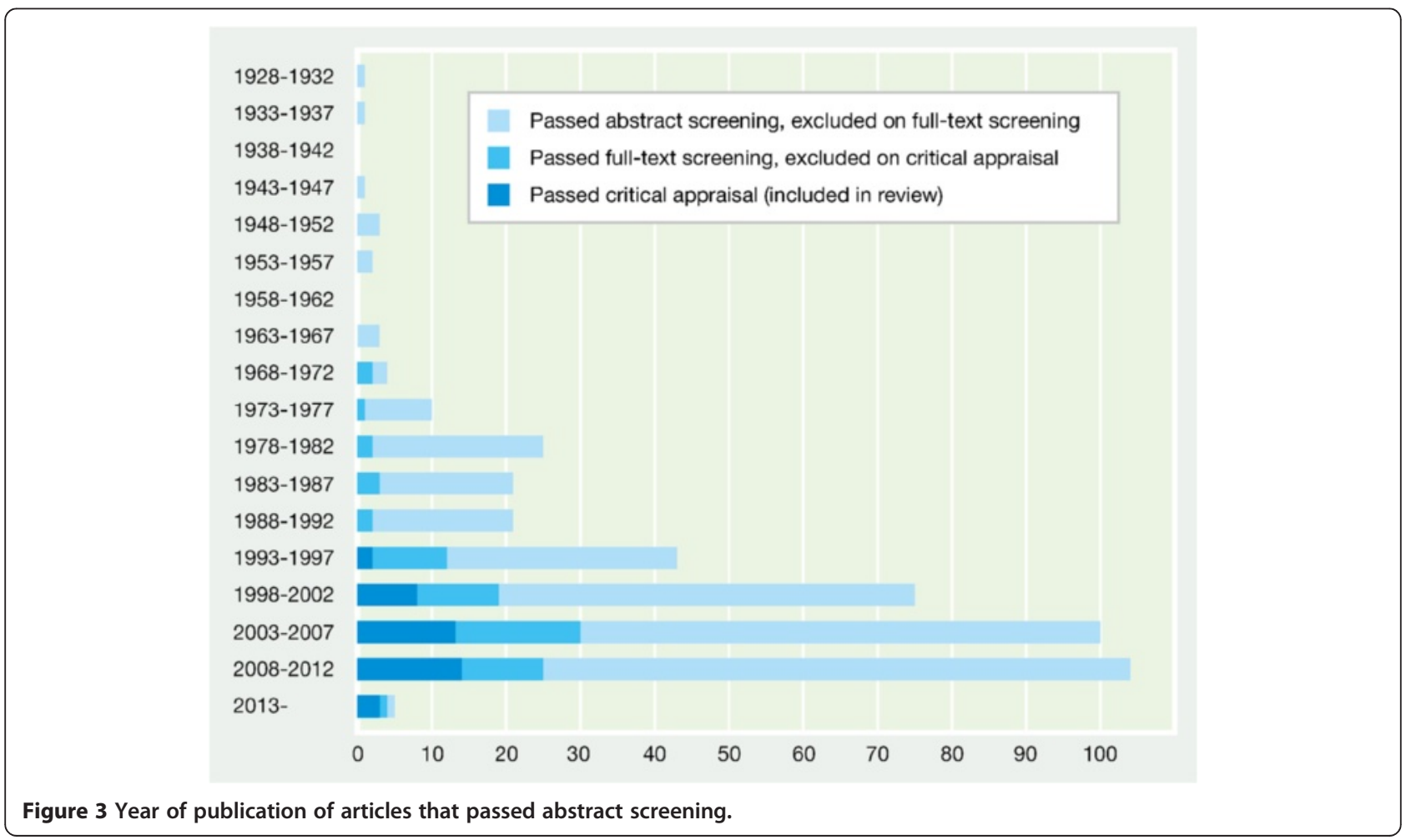




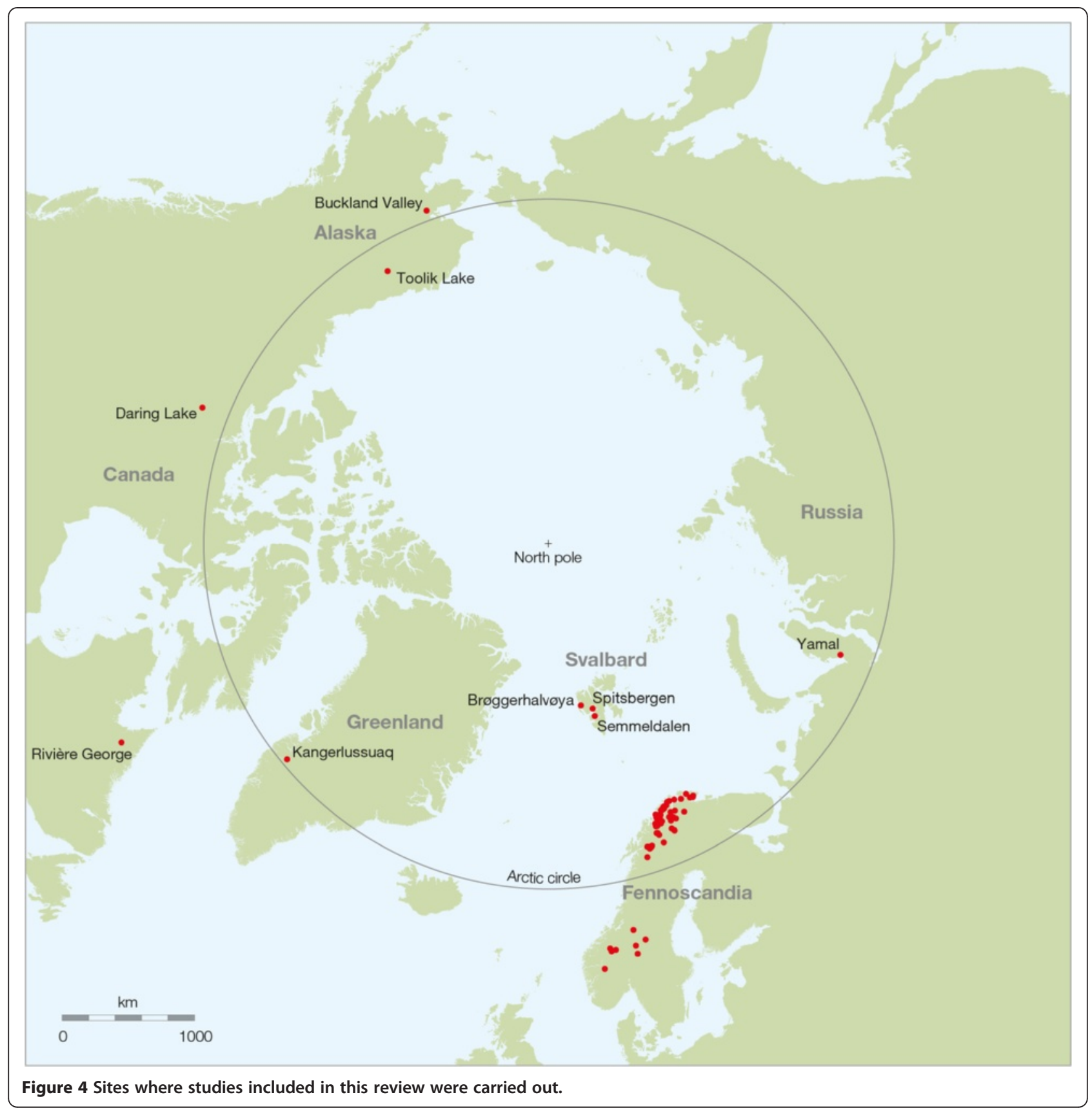

Of the 41 included studies, 30 had a CI design, based on sampling inside and outside reindeer exclosures, in districts with different reindeer densities, or at various distances from a border fence. BA design had been applied in 6 studies, 2 of which were based on remote sensing. The remaining 5 studies had a BACI design based on sampling inside and outside exclosures. See Figure 6 and Additional file 5 for further details on the characteristics of included studies.

Quantitative data have been extracted from 35 of the 41 included studies. These data consist of a total of
2,143 pairs of BA or CI outcomes (or quadruples of BACI outcomes). Almost three quarters of these outcomes $(1,595$ of them) originate from four of the studies $[23,24,62,63]$ and have been supplied as raw data.

Most of the extracted outcomes are comparisons of the cover (762 cases), abundance (668 cases), biomass (271 cases), Shannon or Simpson diversity (242 cases), or species richness (137 cases) of a group or species of vegetation that had been exposed to different levels of reindeer herbivory. See Table 2 for an overview of the most frequently covered groups and species. 


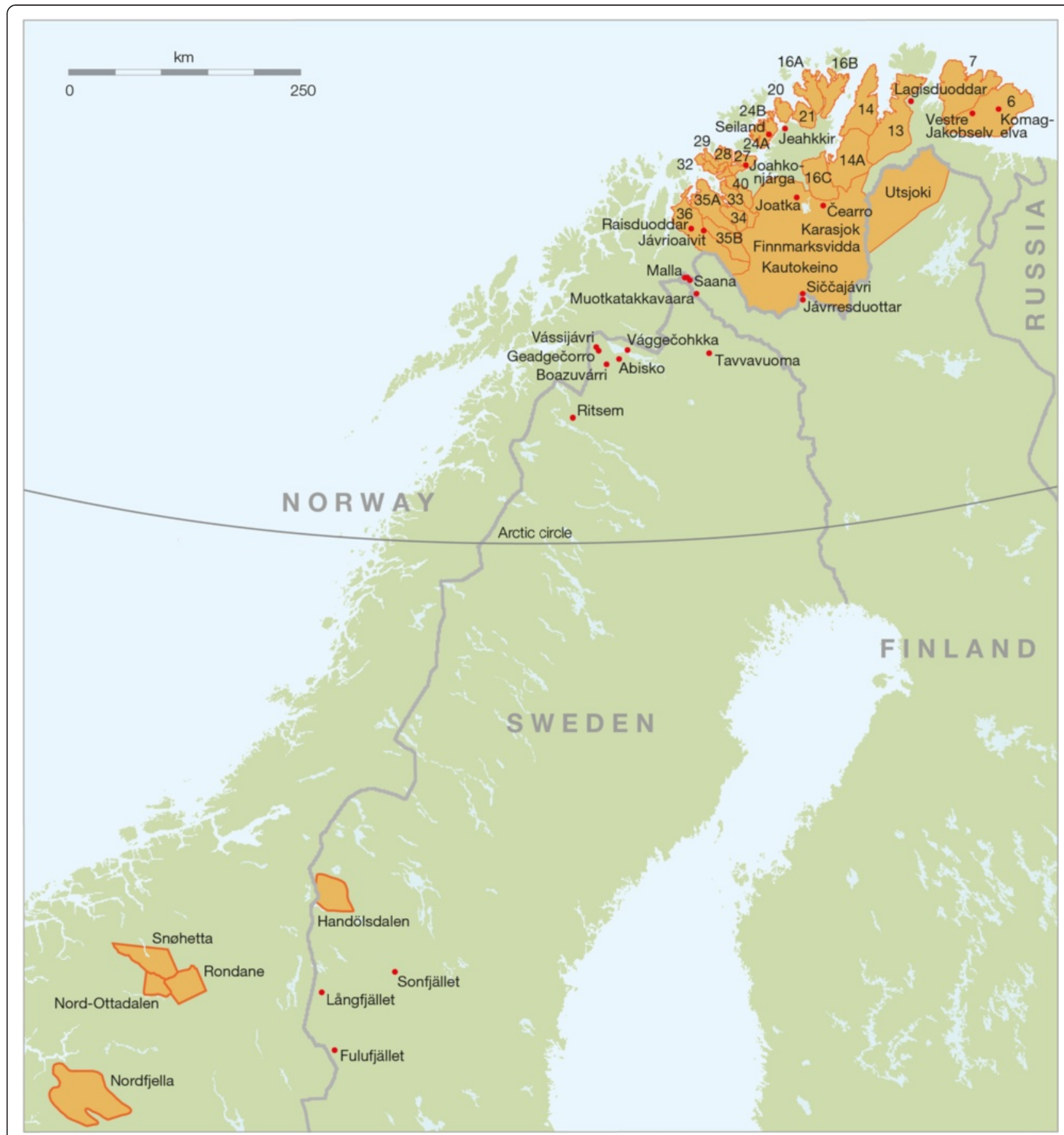

Figure 5 Fennoscandian sites, districts or ranges where studies included in this review were carried out. Numbers refer to Norwegian reindeer-herding districts (see Table $B$ in Additional file 5).

Nearly $80 \%$ of the extracted data refer to single species rather than functional or taxonomic groups of vegetation, but an individual species was rarely covered by more than 1-3 of the included studies. For that reason, we eventually decided not to analyse single-species data in this review. Instead, we have focused on the 455 comparisons of vegetational groups that were available.

\section{Narrative synthesis}

We begin with a narrative synthesis in order to provide context and background for the quantitative metaanalyses that follow. An overview of the included studies can be found in Table A in Additional file 5, with Table B in the same file providing data on the sites or regions where the studies were carried out. The tables are subdivided based on the geographic distribution of the studies. 


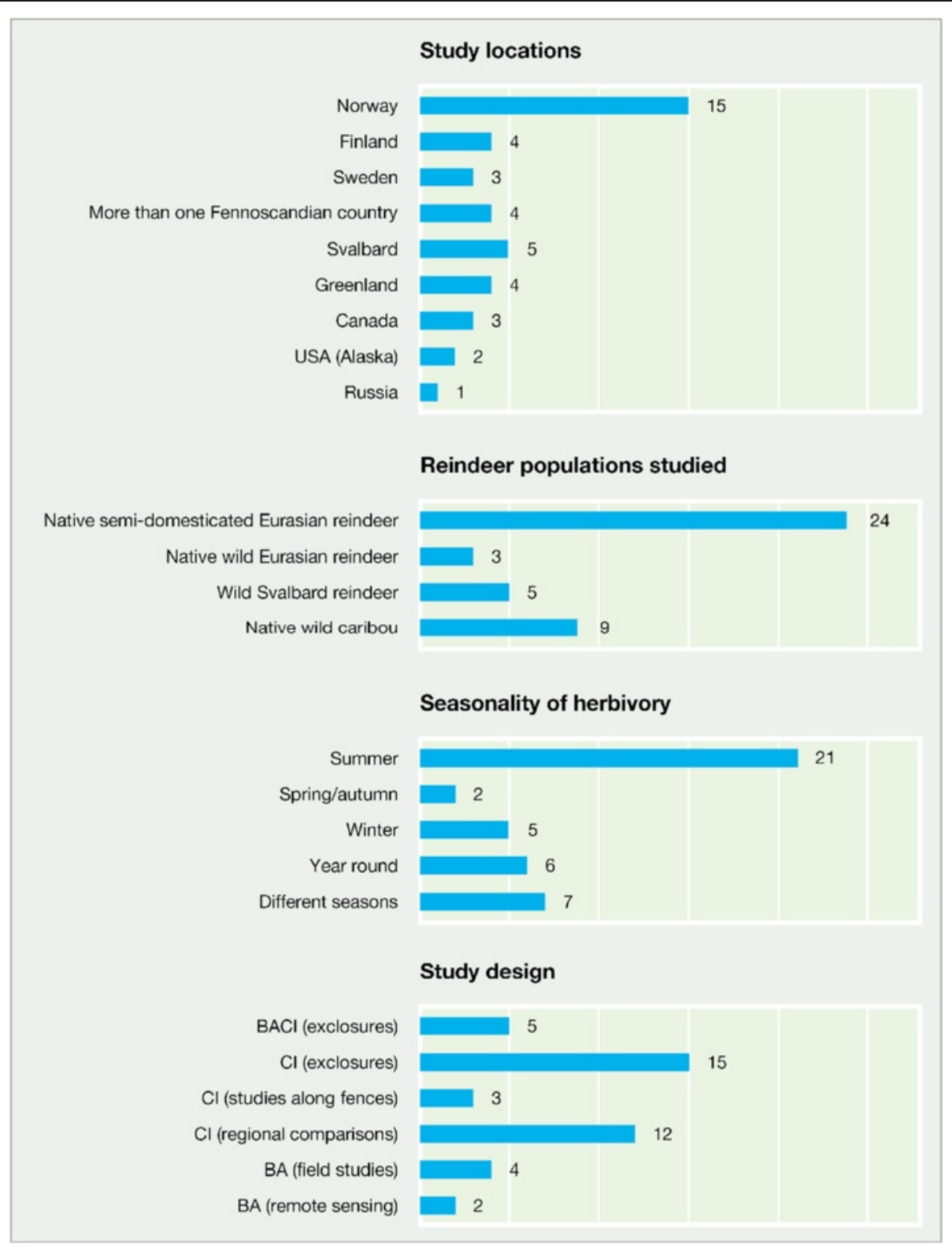

Figure 6 Numbers of included studies with different characteristics.

One of the columns in Table A summarises the effects of reindeer herbivory as reported by the respective authors of the studies. The results often show divergent responses of the vegetation. For instance, Olofsson et al. [21] found increased graminoid cover with increased herbivory at two sites but a non-significant response at two other sites. Similarly, Ravolainen et al. [64] found a negative response of forb biomass at one site and a nonsignificant response at another site. Responses also varied between studies. For instance, Zamin \& Grogan [65] showed positive effects on species richness of vascular plants, while Olofsson \& Oksanen [49], Kitti et al. [66] and Olofsson [67] all showed non-significant effects.
In Finnmark, northern Norway, an interesting remotesensing study was done on the recovery of lichendominated vegetation after a decline in reindeer densities [46]. In the 1980 s, the reindeer populations had more than doubled in the area [58]. This caused a strong decline in lichen cover over a large area $\left(>15,000 \mathrm{~km}^{2}\right)$; average lichen cover in five herding districts in the area changed from $25 \%$ in 1973 to $1.6 \%$ in 2000 as estimated through remote sensing [58]. Beginning around 1990, the reindeer populations were reduced [42], and Tømmervik et al. [46] showed that the recovery of the lichen cover was very rapid. Cover increased 8.6-fold from 1998 to 2005, and the increase 
Table 2 Numbers of extracted comparisons

\begin{tabular}{|c|c|c|c|c|c|c|}
\hline & Abundance & Biomass & Cover & Species richness & Shannon diversity & Simpson diversity \\
\hline Total vegetation & & $12(4)$ & & $18(4)$ & $15(2)$ & $17(3)$ \\
\hline Bare ground & & & $34(6)$ & & & \\
\hline \multicolumn{7}{|l|}{ Groups of vegetation } \\
\hline Vascular plants & & $5(2)$ & $14(2)$ & $21(5)$ & $19(3)$ & $15(2)$ \\
\hline Shrubs, deciduous & $13(3)$ & $5(2)$ & & & & \\
\hline Herbs/forbs & $14(4)$ & $8(4)$ & $20(5)$ & & & \\
\hline Graminoids & $2(2)$ & $4(3)$ & $11(7)$ & & & \\
\hline Grasses & $13(3)$ & $5(2)$ & & & & \\
\hline Sedges & & $5(2)$ & & & & \\
\hline Cryptogams, non-vascular & & & & $15(2)$ & $15(2)$ & $15(2)$ \\
\hline Lichens & $3(2)$ & $7(5)$ & $50(14)$ & $5(2)$ & & \\
\hline Bryophytes & $3(2)$ & & $21(6)$ & $5(2)$ & & \\
\hline Mosses & & & $26(6)$ & & & \\
\hline Liverworts & & & $20(2)$ & & & \\
\hline
\end{tabular}

\section{Single species}

Agrostis capillaris

Alectoria ochroleuca

$11(2)$

Betula nana

4 (2)

3 (2)

Bistorta vivipara

$12(2)$

12 (4)

21 (5)

Calluna vulgaris

7 (2)

Carex bigelowii

11 (2)

Carex spp.

Cetraria islandica

$13(3)$

Cetraria nivalis

Cladina alpestris

Cladina mitis

Cladina rangiferina

Deschampsia flexuosa

$13(3)$

Dicranum spp.

3 (2)

Empetrum

Festuca ovina

$15(5)$

$13(3)$

3 (2)

Hylocomium splendens

Juncus trifidus

5 (2)

Lycopodium annotinum

$12(3)$

Nardus stricta

5 (2)

Phegopteris connectilis

$14(4)$

Phyllodoce caerulea

3 (2)

Rubus chamaemorus

$11(2)$

$4(2)$

$2(2)$

Salix herbaced

$12(3)$

4 (2)

7 (2)

5 (2) $\quad 8$ (3)

$4(2) \quad 12(3)$

3 (2)

3 (2)

17 (4)

$10(2)$

$14(2)$

Salix spp.

7 (3)

Solidago virgaurea

$12(3)$

Sphagnum spp. 
Table 2 Numbers of extracted comparisons (Continued)

\begin{tabular}{|c|c|c|c|}
\hline Trientalis europaea & $12(3)$ & & \\
\hline Vaccinium myrtillus & $14(4)$ & $10(2)$ & \\
\hline Vaccinium uliginosum & & $12(3)$ & $15(4)$ \\
\hline Vaccinium vitis-idaea & $15(5)$ & $10(2)$ & $16(3)$ \\
\hline Viola biflora & & & $3(2)$ \\
\hline
\end{tabular}

Figures in brackets indicate the number of studies from which data have been extracted. Data are shown for groups (or species) and aspects of vegetation covered by at least 2 studies.

was faster on leeward ridges than on exposed ones. The increase rate was inversely related to changes in reindeer densities, and positively related to mean summer precipitation. The authors conclude that the rapid transition from barren ground to a flourishing lichen-dominated vegetation suggests that vegetation degradation by grazing and trampling is reversible [46].

\section{Quantitative synthesis/Meta-analysis}

We have performed quantitative syntheses (meta-analyses) of data extracted from 31 of the 41 included studies. Some of the 10 studies that appear in the narrative synthesis (Additional file 5) but not in the quantitative one have only reported on responses of single species, or on species aggregations that were not, or were poorly, replicated in other studies, such as the data on leaf area index in Cahoon et al. [68] or seed bank density in Gonzales et al. [69]. There were also a few studies that could not be used in meta-analysis since lack of information on outcome deviances or sample sizes made it impossible to calculate effect sizes.

Like the narrative synthesis, the meta-analyses unraveled a great divergence among responses to reindeer exposure (data on a total of eight vegetation categories, such as lichens, graminoids, etc., are presented in Figures 7 and 8 and Additional files 6 and 7). Both significantly positive and significantly negative average responses could be found in all vegetation categories that were considered. However, most studies had large confidence intervals that included zero effect size. Overall responses (average standardised mean differences of all cover, abundance and biomass data combined) were small. Despite the divergence between studies, the overall response to reindeer exposure was significantly negative for herbs/forbs and lichens. Vascular species richness also responded negatively to an increased grazing pressure.

Funnel plots were created to visually check for systematic heterogeneity and publication bias in the data set. No publication bias was detected.

\section{Effects on growth forms and bare ground}

For herbs/forbs, the overall response to reindeer exposure, including all vegetation categories and aspects (cover, biomass and abundance), was significantly negative with a standardised mean difference (SMD) of -0.28 (CI: $-0.48,-0.09$ ). However, responses of individual plant aspects were not significantly different from zero. Some studies show a high variation of effects. For instance, the study by Brathen et al. [23] showed both significant decreases and increases of forb abundances in different pairwise comparisons between herding districts (mean effect size ranging from -1.01 to 0.43 ).

For graminoids, the overall response was close to zero, although grass abundance showed a significant negative overall effect with a standardised mean difference of -0.25 (CI: $-0.46,-0.03$ ). For this group too, responses varied within and between studies, vegetation categories and aspects. For instance, Bråthen et al. [23] and Tømmervik et al. [46] found significant negative effects in some districts (mean effect size ranging from -1.73 to -0.51), while Olofsson et al. [21], Jandt et al. [60] and Post \& Pedersen [70] found significant positive effects elsewhere (mean effect size ranging from 1.54 to 3.85).

Woody plants showed a non-significant overall response to reindeer exposure. Again, however, responses varied within and between studies, with some individual comparisons showing significant negative responses and others significant positive responses.

Lichens showed a significant negative overall response (SMD: -1.14 , CI: $-2.03,-0.25)$ ). However, even for this group, which is well known to respond negatively to grazing and trampling, abundance showed a nonsignificant but positive response to reindeer exposure (SMD: 0.34, CI: $-0.45,1.12$ ). Bryophytes showed no overall response to reindeer herbivory, while the cover of bare ground showed an overall (non-significant) tendency to increase (SMD: 0.27, CI: -0.06, 0.59).

\section{Effects in relation to reindeer densities}

We used weighted meta-regressions of effect sizes against four different ways of measuring intervention strength (grazing pressure) to see if they explained some of the divergence in the results. As measures of grazing pressure, we used the reindeer density in the highexposure treatment, the absolute and relative differences between high and low densities, and the product of absolute density difference and duration of exposure 


\section{Summary of vegetation responses to reindeer herbivory}

Herbs/forbs, cover

Herbs/forbs, biomass

Herbs/forbs, abundance

Herbs/forbs, overall random effects model

Sedges/rushes, abundance

Sedges, cover

Sedges, biomass

Sedges, abundance

Grasses, silica-rich, biomass

Grasses, cover

Grasses, biomass

Grasses, abundance

Graminoids, cover

Graminoids, biomass

Graminoids, abundance

\section{respons to reindeer herbivory}

Graminoids, overall random effects model

Trees, cover

Shrubs, evergreen, biomass

Shrubs, evergreen, abundance

Shrubs, deciduous, cover

Shrubs, deciduous, biomass

Shrubs, deciduous, abundance

Shrubs (non-forage), cover

Ericoids, deciduous, abundance

Dwarf shrubs, evergreen, abundance

Dwarf shrubs, cover

Woody plants, overall random effects model

$>$

Mean and $95 \%$ C.I.

$-0.10[-0.41,0.22]$

$-0.29[-0.73,0.16]$

$-0.22[-0.50,0.07]$

$-0.28[-0.48,-0.09]$

$0.05[-0.17,0.27]$

$0.14[-0.42,0.70]$

$0.04[-0.40,0.48]$

$0.00[-0.93,0.94]$

$0.55[-0.62,1.72]$

$0.03[-0.42,0.48]$

$0.12[-0.32,0.57]$

$-0.25[-0.46,-0.03]$

$0.25[-0.31,0.81]$

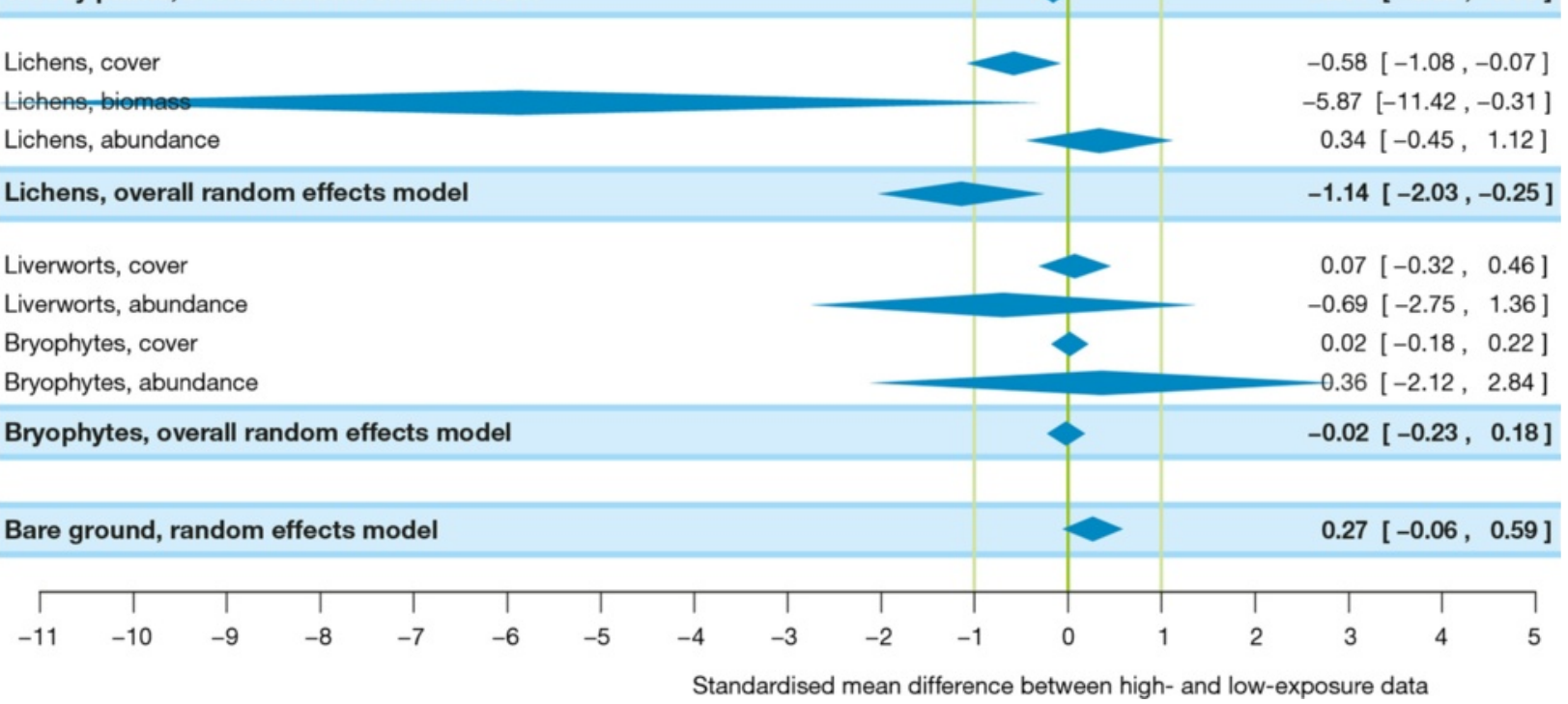

Figure 7 (See legend on next page.) 
(See figure on previous page.)

Figure 7 Summary of meta-analyses of vegetation responses to reindeer herbivory. Subdivisions are based on groups and aspects of vegetation. Positions and widths of the diamond-shaped symbols indicate means and $95 \%$ confidence intervals of effect sizes. A position to the left of the green zero line indicates that the cover, biomass or abundance of vegetation is lower at high exposure to reindeer herbivory than at low exposure, and vice versa. Symbols not intersected by the zero line represent statistically significant effects ( $p<0.05)$. Overall models combine data on cover, biomass and abundance. Individual data are presented in forest plots in Additional file 6

difference (i.e. duration of the experiment). The latter measure can be seen as the difference in number of 'reindeer years'. None of the measures of grazing pressure showed any significant relationship with any of the effect sizes that we had calculated, suggesting either that the reindeer densities were too coarsely estimated, or that reindeer density is context-dependent. We illustrate the lack of pattern with meta-regressions for lichens (all aspects combined) and cover of bare ground (see Additional file 8).

However, when differences of lichen cover are plotted against reindeer densities, it becomes clear that the largest differences occurred at sites where lichen cover was highest (these are also the sites with the lowest reindeer densities; see Figure 9, left). Differences of bare-ground cover in response to reindeer exposure also only occurred at sites where reindeer densities were low (see Figure 9, right).

Indeed, the effect of reindeer on lichen cover was negatively related to average lichen cover, whilst the effect of reindeer on bare-ground cover was positively related to average bare-ground cover (Figure 10). Sites with high reindeer densities already had very low lichen cover (perhaps as a result of grazing or trampling before the studies began) as well as a higher cover of bare ground, and did not respond to the exposure differences during the study period. This shows that the composition of the vegetation is very important in determining the effects of herbivory.

\section{Effects on diversity}

Vascular plant species richness showed a significant negative overall response to reindeer exposure (Figure 8 and Additional file 7; SMD: -0.15 , CI: $-0.25,-0.06)$, but there were no relationships with any of the measures of reindeer densities (see Additional file 8). However, when exploring the diverging responses (ranging from significantly positive to significantly negative), we found them to be significantly related to mean annual temperature (Figure 11; est $=0.138, \mathrm{p}=0.001$ ), suggesting that reindeer exposure tends to increase richness at warmer (more productive) sites and decrease richness at colder (less productive) sites.

Non-vascular cryptogam species richness also showed a negative overall response, but this was not significant (Figure 8 and Additional file 7; SMD: $-0.35, \mathrm{CI}:-1.02$, 0.31 , and we found no relationship to reindeer exposure or temperature.

\section{Stratification by other variables (effect modifiers)}

We tested the effects of the most commonly reported effect modifiers on cover, since that was the aspect of vegetation most frequently represented in our data set. There was not enough data on other combinations of effect modifiers, aspects, and vegetation types to analyse them in a meaningful manner. The clearest differences were related to domestication - wild reindeer tended to have stronger impacts than semi-domesticated ones. For instance, wild reindeer had a negative effect on lichen cover (SMD: $-3.85, \mathrm{CI}$ : -7.17 ,

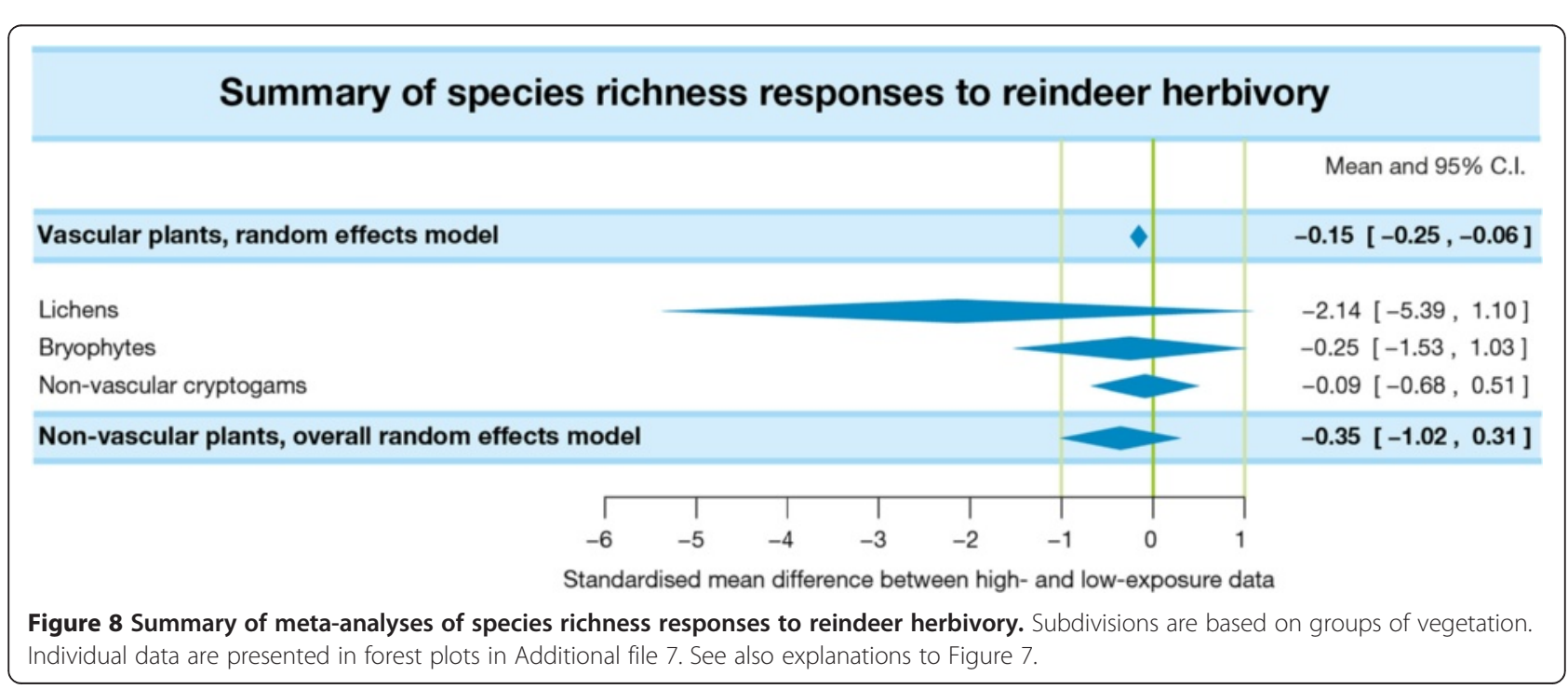




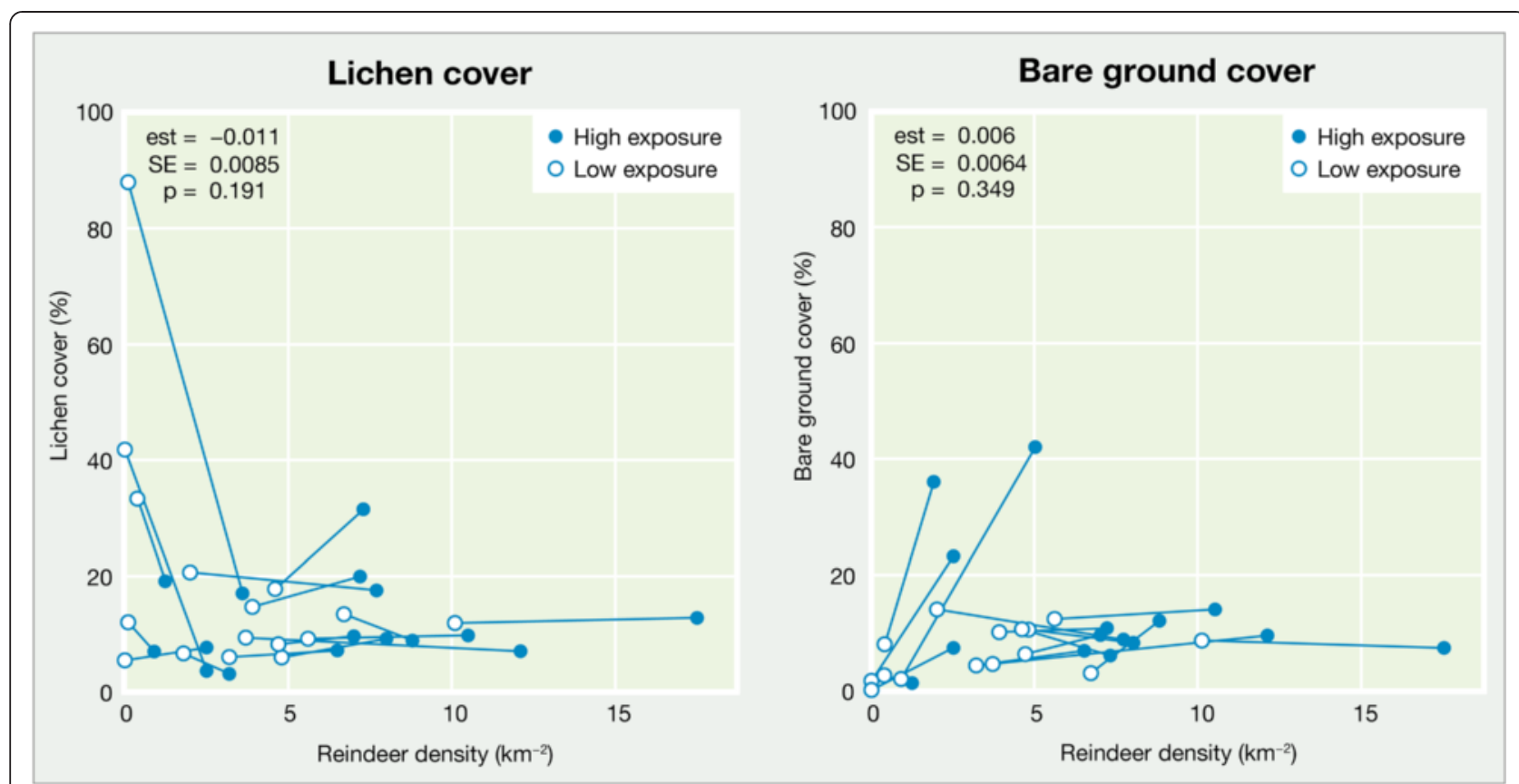

Figure 9 Cover of lichens and bare ground at high and low exposures to grazing. Each pair of symbols (connected by a straight line) represents data from an individual study or site.

$-0.53 ; 5$ studies), while semi-domesticated reindeer had strongly varying effects ranging from negative to positive, giving a mean effect size of zero (CI: $-0.10,0.11)$. Wild reindeer had a positive effect on the cover of graminoids (SMD: 0.74, CI: 0.30, 1.18), while semi-domesticed reindeer had a negative effect (SMD: -0.28 , CI: $-0.51,-0.05)$.
We also tested effects of soil moisture (dry, mesic, wet), habitat type (tundra, forest-tundra ecotone, birch forest), seasonality of grazing (summer-autumn-winter), and exposure type (fencing, exclosures, area comparisons, etc.) on the cover of various groups of vegetation, but no patterns emerged.

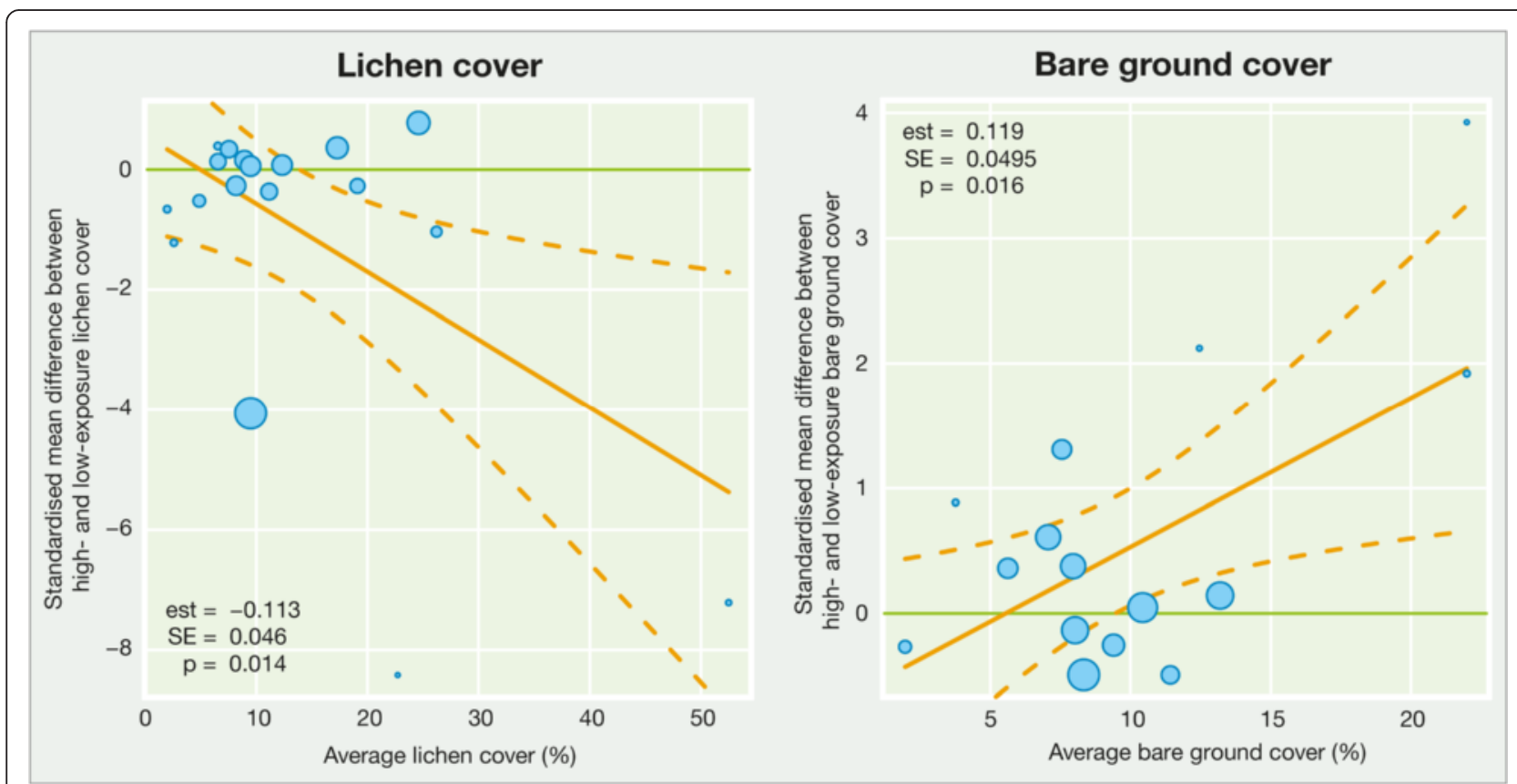

Figure 10 Meta-regressions of lichen and bare-ground cover against average cover of lichens and bare ground. Each symbol represents one study. Symbol sizes are proportional to the inverse variance of effect sizes. 


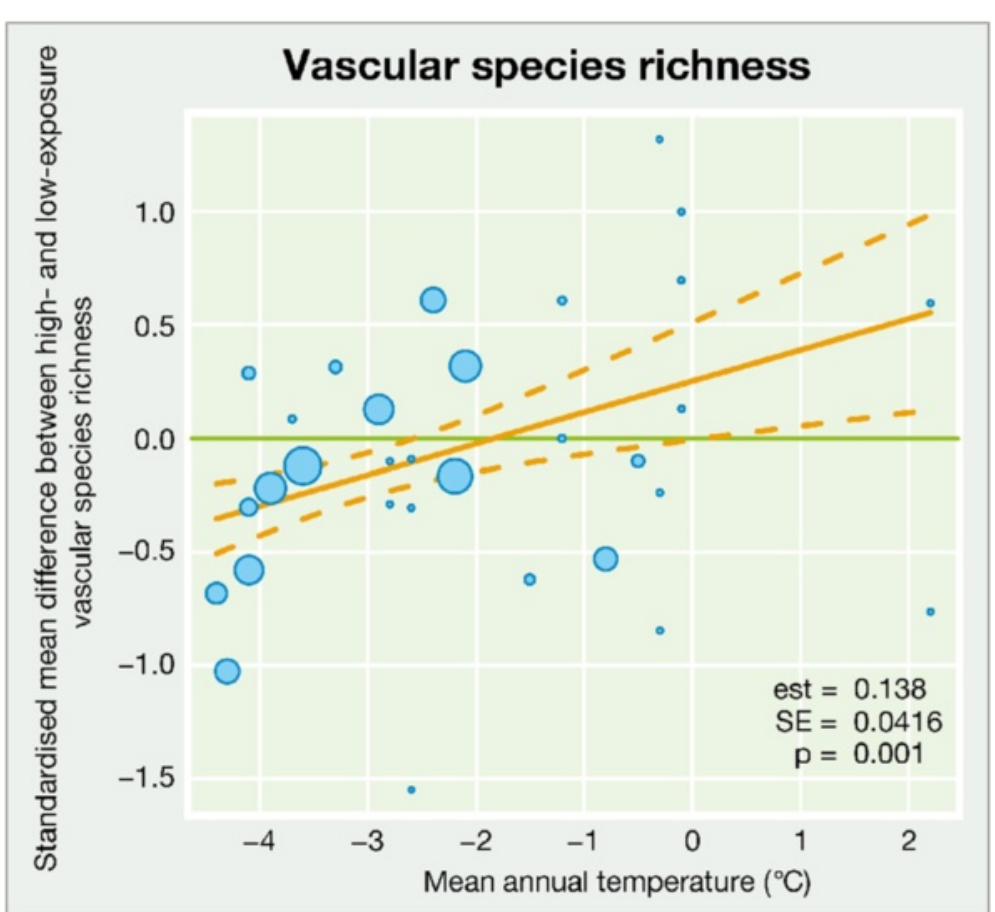

Figure 11 Meta-regression of vascular species richness against mean annual temperature. Each symbol represents one study. Symbol sizes are proportional to the inverse variance of effect sizes.

\section{Discussion}

Overall we found large variations in the effects of reindeer on vegetation, and outcomes seem difficult to predict. However, we did identify a few patterns. 1) We did not find strong evidence that reduction of shrubs by reindeer is a general phenomenon. 2) The overall effect of reindeer on graminoids was neutral, indicating that this supposedly grazing-tolerant growth form is not always promoted by reindeer grazing. 3) We found a reduction of forbs, despite the typically low abundance of this growth form. This indicates that forbs are both highly selected by reindeer and vulnerable. They may be an important indicator group of vascular plants. 4) We were able to corroborate the many studies showing that lichens are vulnerable to reindeer activities. 5) Bryophytes were not vulnerable to reindeer exposure.

In conclusion, the effect of reindeer grazing on arcticalpine vegetation appears to be context-dependent. What, then, could cause this context dependence, i.e. what can explain the heterogeneity of our results?

\section{Reasons for heterogeneity}

The distribution of reindeer encompasses large environmental gradients, ranging from low-productive to highly productive sites, from dry to wet environments and from forests to high alpine tundra, with an entire vegetation mosaic being present within these gradients. All different vegetation types that occur here cannot be expected to respond in the same way to grazing and trampling. For instance, Proulx \& Mazumder [71] showed that species richness tended to decline under grazing at lowproductive sites, but increase at more productive sites. This is mirrored in our study, where vascular-plant species richness was found to be related to mean temperature. Further, the studies included in our analysis ranged from dry ridge vegetation to riparian herb meadows and mesic birch forests, with many different plant communities occurring within those vegetation types. Unfortunately, there was not enough replication at this scale, nor enough consistency in the presentation of plant communities, to analyse grazing effects for each community type.

Seasonality in grazing may also affect the results, especially if grazing in snow-covered terrain is included. However, only about $4 \%$ of the data that we extracted concerned winter grazing, and most of these data were not used in the meta-analyses since they referred to responses of single species. It is thus unlikely that differences in seasonal grazing can explain the heterogeneity we found.

Variations in management systems may be another reason for heterogeneity. Our dataset encompasses impacts of both wild and semi-domesticated reindeer, but with a strong bias towards semi-domesticated herds ( $>90 \%$ of the extracted data). However, management systems were confounded with the initial vegetation state; 
for instance, wild reindeer tended to occur in areas with high lichen cover, which precluded us from testing their influence on the outcomes. Even among semidomesticated herds, management systems vary considerably. Reindeer husbandry operates under many different drivers, forms of legislation, market situations and historical legacies within and between different countries. Grazing pressure may thus vary strongly between different herding districts and systems.

It has been suggested that reindeer have relatively small and subtle overall effects on vegetation in summer grounds. Estimates of biomass removal vary from $0.6 \%$ to $2 \%$ of net primary productivity, and such levels are unlikely to cause large changes in the vegetation [e.g. 1]. The reasons for the low overall effects could include a decoupling of population dynamics and food resources in the more forage-abundant season, [1,72]. Reindeer numbers are generally determined by winter resources, and the summer resources constitute a pulse of plant biomass growth that the reindeer populations cannot fully respond to. However, reindeer do not use the landscape randomly, and grazing pressure may be much higher than average in preferred sites and vegetation types. For instance, Bråthen \& Oksanen [73] estimated a forage removal of preferred plants of the order of $60 \%$.

Heterogeneity is also likely due to the fact that woody plants, often comprising the dominant species in dwarfshrub tundra [8] and being a characteristic component of reindeer ranges, have highly differential qualities. Ranging from evergreen, allelopathic species such as Empetrum nigrum to deciduous ericoids, Betula nana and species of Salix, the woody plants can be sorted in categories of palatability to reindeer, and hence they are likely to be differentially affected by reindeer herbivory. Exceptions may occur close to fences or in corrals, where reindeer densities are locally increased and where trampling may even have an impact on Empetrum [21,49].

\section{Review limitations}

Most of the meta-analyses that we conducted are based on a limited number of studies, and they are heavily influenced by a few large-scale investigations (especially Olofsson et al. [21,26], Bråthen et al. [23], Eriksson et al. [62] and Ravolainen et al. [24,64]), mostly conducted in northern Norway and Sweden. This, together with the lack of a common research protocol (researchers have measured several aspects of vegetation in dissimilar ways), makes it difficult to summarise results across all studies included in our systematic review. For instance, we found data on 16 different types of species groupings among woody plants (including e.g. non-forage shrubs and deciduous ericoids). When combined with different methods of measuring vegetation (abundance, cover, and biomass), this resulted in 23 different subgroups in the meta-analysis. These kinds of study-specific subgroupings and methodologies limit our ability to disentangle under what circumstances reindeer have positive, neutral or negative effects on various aspects of vegetation. This is not a trivial problem, since there are also large environmental and social gradients that need to be addressed.

The studies included in our review are fairly recent (mostly dating from 2000 or later). We have very little data from extended experiments based on true replication that could help us to examine the long-term effects of reindeer herbivory. The included studies are also limited both geographically and in terms of vegetation types, and thus not representative of the distribution of reindeer. Most of the data come from tundra sites, and the database is weak on effects on treelines and subalpine forests.

Most of the studies have merely categorised reindeer densities or grazing pressures at treatment and control sites as high or low, without attempting to quantify them further. However, as Bråthen et al. [23] show, what is regarded as high in one area can be regarded as low in another, making comparisons difficult. In cases where authors have not reported any data on reindeer densities, we have tried to recalculate them from official population records for entire herding districts. Such data are well correlated with indices of grazing pressure in herding districts in Finnmark [23,24], but much less so in the herding districts in Sweden. In fact, this lack of correlation in Sweden was the basis for the Moen et al. study [63], where detailed pellet counts within one herding district were used to distinguish areas with different grazing pressures. As shown in that study, vegetation responses to grazing may vary even within the same district and vegetation type, depending on the actual landscape use of the reindeer. Our estimates of reindeer densities are thus very coarse and possibly misleading.

\section{Conclusions}

Implication for policy/management

While our review has gathered a large body of research into vegetation responses to reindeer grazing, we still have to conclude that the evidence base is too weak and scattered to inform policy or management in a detailed way. Some of the reasons for this are small sample sizes, short duration of experiments, limited geographic distribution of studies, difficulties in determining reindeer population densities, and a lack of common research protocols. The included studies are not standardised and representative enough that they can be used as a basis for specific recommendations regarding reindeer ranges in Sweden, nor in the circumpolar region as a whole.

However, an important point that we can make is that vegetation responses to reindeer grazing are context- 
dependent. For instance, the differential effects of reindeer on vegetation found in this review are most likely due to the variation of vegetation types and dominant growth forms, productivity, and grazing history, just to mention a few important factors. This suggests that there is no panacea that can cover all combinations of factors. Policy and management have to go hand-inhand with research in individual cases if the dynamics between plants, animals, and humans are to be sufficiently understood.

\section{Implication for research and monitoring}

It is unlikely that further research will be able to improve the evidence base much unless a more rigorous research protocol, specifically aimed at the questions raised in this review, becomes generally accepted and implemented. We provide some suggestions for achieving this:

- Adopt a standardised way of aggregating plant species into growth forms and/or functional groups.

- Agree on the aspects of vegetation (biomass, abundance or cover) that should have priority.

- Adopt common measures of vegetation.

- Develop common measures of reindeer densities and grazing/browsing and trampling pressures.

- Implement the protocol in monitoring programs as well as in specific research programs.

- Be very clear in the methods section of an article on how the experiment has been done, and include more information in table and figure captions (such as the number of replicates that the means are based on, and the type of variation that is shown).

- Deposit raw data in public data repositories.

- Include some measure of plant productivity.

- Include some measure of plant palatability and plant nutrition status.

- If possible, adopt a gradient approach to investigate variations in responses.

- External factors, such as the history of land use and reindeer husbandry, should be carefully documented for each study site.

\section{Additional files}

\section{Additional file 1: Literature searches.}

Additional file 2: Excluded articles.

Additional file 3: Reasons for article exclusions.

Additional file 4: Sources of included articles.

Additional file 5: Narrative tables summarising included studies.

Additional file 6: Forest plots, cover/biomass/abundance.

Additional file 7: Forest plots, species richness.

Additional file 8: Meta-regressions against reindeer density.
Competing interests

The authors declare that they have no competing interests.

\section{Authors' contributions}

All authors participated in the drafting, revision and approval of the manuscript.

\section{Acknowledgements}

We wish to thank Robert Björk, Johan Olofsson, Virve Ravolainen and Christina Wegener for helpful responses to our requests for raw data. We also thank Annika Hofgaard for her contributions as chair of the review project during its initial phases, and Neal Haddaway for his advice concerning review methodology during the development of the review protocol. Moreover, we are grateful for suggestions and comments received from stakeholders representing the Swedish Environmental Protection Agency, the Ministry for Rural Affairs, the Sami Parliament, the county administrative boards of Jämtland and Norrbotten, Stockholm University, the Swedish Biodiversity Centre, the Swedish Species Information Centre, the Swedish Polar Research Secretariat, and Ájtte (Swedish Mountain and Sami Museum). This systematic review has been financed by the Mistra Council for EvidenceBased Environmental Management (EviEM). EviEM is funded by the Swedish Foundation for Strategic Environmental Research (Mistra) and hosted by the Royal Swedish Academy of Sciences. The review process has been approved by the EviEM Executive Committee, but the authors are solely responsible for the contents and conclusions of the review.

\section{Author details}

${ }^{1}$ Mistra Council for Evidence-Based Environmental Management, Royal Swedish Academy of Sciences, P.O. Box 50005, SE-104 05 Stockholm, Sweden.

${ }^{2}$ Department of Arctic and Marine Biology, University of Tromsø, NO-9037 Tromsø, Norway. ${ }^{3}$ Arctic Centre, University of Lapland, P.O. Box 122, FIN-96101 Rovaniemi, Finland. ${ }^{4}$ University Museum, Norwegian University of Science and Technology, NO-7491 Trondheim, Norway. ${ }^{5}$ Department of Ecology and Environmental Science, Umeå University, SE-901 87 Umeå, Sweden.

Received: 6 October 2014 Accepted: 22 December 2014

Published online: 23 February 2015

\section{References}

1. Moen J, Andersen R, Illius AW. Living in a seasonal environment. In: Danell K, Bergström R, Duncan P, Pastor J, editors. Large Herbivore Ecology, Ecosystem Dynamics and Conservation. Cambridge: Cambridge University Press; 2006. p. 50-70.

2. Helle TP, Jaakkola LM. Transitions in herd management of semidomesticated reindeer in northern Finland. Ann Zool Fennici. 2008:45:81-101.

3. Renbetesmarksutredningen. Renbetesmarkerna. Stockholm: SOU 12; 1966.

4. Tømmervik H, Riseth JÅ. Historiske tamreintall i Norge fra 1800 -tallet fram til i dag. Tromsø: NINA; 2011. Rapport 672.

5. Kortesalmi JJ. Poronhoidon synty ja kehitys Suomessa. Tampere: TammerPaino Oy; 2007.

6. Ims RA, Ehrich D, Forbes BC, Huntley B, Walker DA, Wookey PA, et al. Terrestrial Ecosystems. In: Meltofte H, editor. Arctic Biodiversity Assessment. Status and Trends in Arctic Biodiversity. Akureyri: Conservation of Arctic Flora and Fauna; 2013. p. 385-440.

7. McNaughton SJ, Oesterheld M, Frank DA, Williams KJ. Ecosystem-level patterns of primary productivity and herbivory in terrestrial habitats. Nature. 1989;341:142-4.

8. Walker DA, Raynolds MK, Daniels FJA, Einarsson E, Elvebakk A, Gould WA et al. The circumpolar arctic vegetation map. J Vegetation Sci. 2005;16:267-82.

9. Storeheier PV, Mathiesen SD, Tyler NJC, Olsen MA. Nutritive value of terricolous lichens for reindeer in winter. Lichenologist. 2002;34:247-57.

10. Sørmo W, Haga ØE, Gaare E, Langvatn R, Mathiesen SD. Forage chemistry and fermentation chambers in Svalbard reindeer (Rangifer tarandus platyrhynchus). J Zool. 1999;247:247-56.

11. van der Wal R. Do herbivores cause habitat degradation or vegetation state transition? Evidence from the tundra. Oikos. 2006:114:177-86.

12. Dahlberg A, Bültmann H. Fungi. In: Meltofte H, editor. Arctic Biodiversity Assessment. Status and Trends in Arctic Biodiversity. Akureyri: Conservation of Arctic Flora and Fauna; 2013. p. 354-71 
13. Nieminen $M$, Heiskari U. Diets of freely grazing and captive reindeer during summer and winter. Rangifer. 1989;9:17-34.

14. Jefferies RL, Klein DR, Shaver GR. Vertebrate herbivores and northern plant communities. Reciprocal influences and responses. Oikos. 1994;71:193-206.

15. Iversen M, Fauchald $P$, Langeland $K$, Ims RA, Yoccoz NG, Bråthen KA. Phenology and cover of plant growth forms predict herbivore habitat selection in a high latitude ecosystem. PLoS One. 2014;9(6):e100780.

16. Chapin FS, BretHarte MS, Hobbie SE, Zhong HL. Plant functional types as predictors of transient responses of arctic vegetation to global change. J Vegetation Sci. 1996;7:347-58.

17. Wookey PA, Aerts R, Bardgett RD, Baptist F, Bråthen KA, Cornelissen JHC, et al. Ecosystem feedbacks and cascade processes: understanding their role in the responses of Arctic and alpine ecosystems to environmental change. Glob Chang Biol. 2009;15:1153-72.

18. Mårell A, Hofgaard A, Danell K. Nutrient dynamics of reindeer forage species along snowmelt gradients at different ecological scales. Basic and Appl Ecol. 2006;7:13-30

19. Iversen $M$, Bråthen KA, Yoccoz NG, Ims RA. Predictors of plant phenology in a diverse high-latitude alpine landscape: growth forms and topography. J Vegetation Sci. 2009;20:903-15.

20. van der Wal R, Brooker RW. Mosses mediate grazer impacts on grass abundance in arctic ecosystems. Function Ecol. 2004;18:77-86.

21. Olofsson J, Kitti H, Rautiainen P, Stark S, Oksanen L. Effects of summer grazing by reindeer on composition of vegetation, productivity and nitrogen cycling. Ecography. 2001;24:13-24.

22. Olofsson J, Stark S, Oksanen L. Reindeer influence on ecosystem processes in the tundra. Oikos. 2004;105:386-96.

23. Bråthen KA, Ims RA, Yoccoz NG, Fauchald P, Tveraa T, Hausner V. Induced shift in ecosystem productivity? Extensive scale effects of abundant large herbivores. Ecosystems. 2007;10:773-89.

24. Ravolainen V, Yoccoz N, Bråthen KA, Ims RA, Iversen M, Gonzalez V. Additive partitioning of diversity reveals no scale-dependent impacts of large ungulates on the structure of tundra plant communities. Ecosystems. 2010;13:157-70.

25. Cairns DM, Moen J. Herbivory influences tree lines. J Ecol. 2004;92:1019-24.

26. Olofsson J, Oksanen L, Callaghan T, Hulme PE, Oksanen T, Suominen O. Herbivores inhibit climate-driven shrub expansion on the tundra. Global Change Biol. 2009;15:2681-93.

27. Ravolainen VT, Bråthen KA, Yoccoz NG, Nguyen JK, Ims RA. Complementary impacts of small rodents and semi-domesticated ungulates limit tall shrub expansion in the tundra. J Appl Ecol. 2014;51:234-41.

28. Ims RA, Henden JA. Collapse of an arctic bird community resulting from ungulate-induced loss of erect shrubs. Biol Conserv. 2012;149:2-5.

29. Olff $H$, Ritchie ME. Effects of herbivores on grassland plant diversity. Trends Ecol Evol. 1998:13:261-5.

30. Milchunas D, Sala O, Lauenroth WK. A generalized model of the effects of grazing by large herbivores on grassland community structure. Am Nat. 1988;132:87-106

31. Forbes BC, Kumpula T. The ecological role and geography of reindeer (Rangifer tarandus) in northern Eurasia. Geography Compass. 2009:3/4:1356-80.

32. Forbes BC, Stammler F, Kumpula T, Meschtyb N, Pajunen A, Kaarlejärvi E. High resilience in the Yamal-Nenets social-ecological system, West Siberian Arctic, Russia. PNAS. 2009;106:22041-8.

33. Tveraa $T$, Ballesteros $M$, Bårdsen $B J$, Fauchald $P$, Lagergren $M$, Langeland $K$, et al. Rovvilt og reindrift - Kunnskapsstatus i Finnmark. Tromsø: NINA; 2012 Rapport 821.

34. Swedish EPA. Förslag till en strategi för miljökvalitetsmålet Storslagen fjällmiljö. Naturvårdsverket, Stockholm: Naturvårdsverket; 2014

35. Larsen JN, Anisimov OA, Constable A, Hollowed A, Maynard N, Prestrud P, et al. Polar regions. In: Climate Change 2014: Impacts, Adaptation, and Vulnerability. Working Group II contribution to Intergovernmental Panel on Climate Change - 5th Assessment Report. Geneva: WMO/UNEP; 2014. Chapter 28.

36. ACIA. Arctic Climate Impact Assessment. Cambridge: Cambridge University Press; 2005.

37. Verbyla D. The greening and browning of Alaska based on 1982-2003 satellite data. Global Ecol Biogeogr. 2008;17:547-55.

38. Macias-Fauria M, Forbes BC, Zetterberg P, Kumpula T. Eurasian Arctic greening reveals teleconnections and the potential for structurally novel ecosystems. Nat Clim Chang. 2012;2:613-8.
39. Xu L, Myneni RB, Chapin III FS, Callaghan TV, Pinzon JE, Tucker CJ, et al Temperature and vegetation seasonality diminishment over northern lands. Nat Clim Chang. 2013;3:581-6.

40. Moen J. Climate change: effects on the ecological basis for reindeer husbandry in Sweden. Ambio. 2008;37:304-11.

41. Cohen J, Pullianen J, Menard CB, Johansen B, Oksanen L, Luojos K, et al. Effect of reindeer grazing on snowmelt, albedo and energy balance based on satellite data analyses. Remote Sens Environ. 2013;135:107-17.

42. Moen J, Danell Ö. Reindeer in the Swedish mountains: An assessment of grazing impacts. Ambio. 2003;32:397-402.

43. Swedish Ministry of the Environment. Hållbar utveckling i landet fjällområden. Stockholm: Government Bill 1995/96:226; 1996.

44. Johansen B, Tømmervik H. Finnmarksvidda - vegetasjonskartlegging Tromsø: FORUT; 1992.

45. Käyhkö J, Pellikka P. Remote sensing of the impact of reindeer grazing on vegetation in northern Fennoscandia using SPOT XS data. Polar Res. 1994;13:115-24.

46. Tømmervik H, Bjerke JW, Gaare E, Johansen B, Thannheiser D. Rapid recovery of recently overexploited winter grazing pastures for reindeer in northern Norway. Fungal Ecol. 2012:5:3-15.

47. Linkowski Wl, Lennartsson T: Renbete och biologisk mångfald kunskapssammanställning. Luleå: Länsstyrelsen i Norrbottens län, Rapport 18/2006; 2006

48. Swedish Ministry of the Environment. Svenska miljömål. Miljöpolitik för ett hållbart Sverige. Stockholm: Government Bill 1997/98:145; 1998.

49. Olofsson J, Oksanen L. Effects of reindeer density on vascular plant diversity on North Scandinavian mountains. Rangifer. 2005;25:5-18.

50. Bernes C, Bråthen KA, Forbes BC, Hofgaard A, Moen J, Speed JDM. What are the impacts of reindeer/caribou (Rangifer tarandus L.) on arctic and alpine vegetation? A systematic review protocol. Environ Evidence. 2013;2:6.

51. Collaboration for Environmental Evidence: Guidelines for systematic review and evidence synthesis in environmental management. Version 4.2, p. 37. Environmental Evidence: www.environmentalevidence.org/Documents/ Guidelines/Guidelines4.2.pdf; 2013.

52. Mysterud A. The concept of overgrazing and its role in management of large herbivores. Wildl Biol. 2006;12:129-41.

53. Suominen O, Olofsson J. Impacts of semi-domesticated reindeer on structure of tundra and forest communities in Fennoscandia: A review. Ann Zool Fennici. 2000;37:233-49.

54. Landis JR, Koch GG. The measurement of observer agreement for categorical data. Biometrics. 1977;33:159-74.

55. Hijmans RJ, Cameron SE, Parra JL, Jones PG, Jarvis A. Very high resolution interpolated climate surfaces for global land areas. Int J Climatol. 2005:25:1965-78.

56. Viechtbauer W. Conducting meta-analyses in $\mathrm{R}$ with the metafor package. J Stat Softw. 2010;36:1-48.

57. R Core Team: R: A language and environment for statistical computing Vienna: R Foundation for Statistical Computing; 2013. http://www.Rproject.org/

58. Johansen B, Karlsen SR. Monitoring vegetation changes on Finnmarksvidda, Northern Norway, using Landsat MSS and Landsat TM/ETM+ satellite images. Phytocoenologia. 2005;35:969-84.

59. Gaare E, Tømmervik H, Bjerke JW, Thannheiser D. Overvåking av vinterbeiter i Vest-Finnmark og Karasjok: Ny beskrivelse av fastrutene. Trondheim and Tromsø: Norsk institutt for naturforskning; 2006. Rapport 204

60. Jandt RR, Meyers CR, Cole M J: Western Arctic Caribou Herd winter habitat monitoring and utilization, 1995-1996. Anchorage: Bureau of Land Management, US Dept. of the Interior, BLM-Alaska Open File Report 88; 2003.

61. Hansen BB, Henriksen S, Aanes R, Sæther B-E. Ungulate impact on vegetation in a two-level trophic system. Polar Biol. 2007;30:549-58.

62. Eriksson O, Niva M, Caruso A. Use and abuse of reindeer range. Acta Phytogeogr Suecica. 2007;87:1-88.

63. Moen J, Boogerd C, Skarin A. Variations in mountain vegetation use by reindeer (Rangifer tarandus) affects dry heath but not grass heath. J Veg Sci. 2009;20:805-13.

64. Ravolainen VT, Bråthen KA, Ims RA, Yoccoz NG, Henden JA, Killengreen ST. Rapid, landscape scale responses in riparian tundra vegetation to exclusion of small and large mammalian herbivores. Basic Appl Ecol. $2011 ; 12: 643-53$ 
65. Zamin TJ, Grogan P. Caribou exclusion during a population low increases deciduous and evergreen shrub species biomass and nitrogen pools in low Arctic tundra. J Ecol. 2013;101:671-83.

66. Kitti $\mathrm{H}$, Forbes BC, Oksanen J. Long- and short-term effects of reindeer grazing on tundra wetland vegetation. Polar Biol. 2009;32:253-61.

67. Olofsson J. Short- and long-term effects of changes in reindeer grazing pressure on tundra heath vegetation. J Ecol. 2006;94:431-40.

68. Cahoon SMP, Sullivan PF, Post E, Welker JM. Large herbivores limit $\mathrm{CO}_{2}$ uptake and suppress carbon cycle responses to warming in West Greenland. Global Change Biol. 2012:18:469-79.

69. Gonzalez VT, Bråthen KA, Ravolainen VT, Iversen M, Hagen SB. Large-scale grazing history effects on Arctic-alpine germinable seed banks. Plant Ecol. 2010;207:321-31.

70. Post E, Pedersen C. Opposing plant community responses to warming with and without herbivores. PNAS. 2008;105:12353-8.

71. Proulx M, Mazumder A. Reversal of grazing impact on plant species richness in nutrient-poor vs. nutrient-rich ecosystems. Ecology. 1998;79:2581-92.

72. Illius AW, O'Connor TG. Resource heterogeneity and ungulate population dynamics. Oikos. 2000;89:283-94.

73. Bråthen KA, Oksanen J. Reindeer reduce biomass of preferred plant species. J Veg Sci. 2001;12:473-80.

74. den Herder M, Virtanen R, Roininen $\mathrm{H}$. Effects of reindeer browsing on tundra willow and its associated insect herbivores. J Appl Ecol. 2004:41:870-9.

75. Dormann CF, Skarpe C. Flowering, growth and defence in the two sexes: Consequences of herbivore exclusion for Salix polaris. Funct Ecol. 2002;16:649-56.

76. Eskelinen A, Oksanen J. Changes in the abundance, composition and species richness of mountain vegetation in relation to summer grazing by reindeer. J Veg Sci. 2006;17:245-54.

77. Gough L, Shrestha K, Johnson DR, Moon B. Long-term mammalian herbivory and nutrient addition alter lichen community structure in Alaskan dry heath tundra. Arct Antarct Alp Res. 2008;40:65-73.

78. Grellmann D. Plant responses to fertilization and exclusion of grazers on an arctic tundra heath. Oikos. 2002;98:190-204.

79. Lehtonen J, Heikkinen RK. On the recovery of mountain birch after Epirrita damage in Finnish Lapland, with a particular emphasis on reindeer grazing. Ecoscience. 1995;2:349-56.

80. Manseau M, Huot J, Crête M. Effects of summer grazing by caribou on composition and productivity of vegetation: Community and landscape level. J Ecol. 1996:84:503-13.

81. Nellemann C, Jordhøy P, Støen OG, Strand O. Cumulative impacts of tourist resorts on wild reindeer (Rangifer tarandus tarandus) during winter. Arctic. 2000:53:9-17.

82. Nellemann C, Vistnes I, Jordhøy P, Strand O. Winter distribution of wild reindeer in relation to power lines, roads and resorts. Biol Conservation. 2001;101:351-60

83. Olofsson J, Strengbom J. Response of galling invertebrates on Salix lanata to reindeer herbivory. Oikos. 2000;91:493-8.

84. Olofsson J, Hulme PE, Oksanen L, Suominen O. Importance of large and small mammalian herbivores for the plant community structure in the forest tundra ecotone. Oikos. 2004;106:324-34.

85. Olofsson J, te Beest M, Ericson L. Complex biotic interactions drive longterm vegetation dynamics in a subarctic ecosystem. Phil Trans Roy Soc B. 2013:368:20120486.

86. Pajunen AM. Environmental and biotic determinants of growth and height of arctic willow shrubs along a latitudinal gradient. Arct Antarct Alp Res. 2009:41:478-85

87. Pedersen C, Post E. Interactions between herbivory and warming in aboveground biomass production of arctic vegetation. BMC Ecol. 2008;8:17.

88. Post E. Erosion of community diversity and stability by herbivore removal under warming. Proc Roy Soc B. 2013;280:20122722.

89. Tømmervik H, Johansen B, Riseth JÅ, Karlsen SR, Solberg B, Høgda KA. Above ground biomass changes in the mountain birch forests and mountain heaths of Finnmarksvidda, northern Norway, in the period 1957-2006. Forest Ecol Manage. 2009;257:244-57.

90. van der Wal R, Brooker R, Cooper E, Langvatn R. Differential effects of reindeer on high Arctic lichens. J Veg Sci. 2001;12:705-10.

91. Vistnes I, Nellemann C, Jordhøy P, Strand O. Effects of infrastructure on migration and range use of wild reindeer. J Wildlife Manage. 2004;68:101-8.

92. Zamin TJ, Grogan P. Birch shrub growth in the low Arctic: The relative importance of experimental warming, enhanced nutrient availability, snow depth and caribou exclusion. Environ Res Lett. 2012;7:034027.

\section{Submit your next manuscript to BioMed Central and take full advantage of:}

- Convenient online submission

- Thorough peer review

- No space constraints or color figure charges

- Immediate publication on acceptance

- Inclusion in PubMed, CAS, Scopus and Google Scholar

- Research which is freely available for redistribution

Submit your manuscript at www.biomedcentral.com/submit 